\title{
Revision of Dadagulella gen. nov., the "Gulella radius group" (Gastropoda: Streptaxidae) of the eastern Afrotropics, including six new species and three new subspecies
}

\author{
Ben ROWSON ${ }^{1} \&$ Peter TATTERSFIELD ${ }^{2}$ \\ 1,2 Biodiversity \& Systematic Biology, National Museum of Wales, Cathays Park, Cardiff, UK CF10 3NP. \\ Email: ben.rowson@museumwales.ac.uk \\ ${ }^{1}$ urn:Isid:zoobank.org:author:05D46259-DA45-45A4-9127-5AF361D566A7 \\ ${ }^{2}$ urn:Isid:zoobank.org:author:8C55642E-B18A-461B-9BF9-31CB6DB7A070
}

\begin{abstract}
The genus Dadagulella gen. nov. is described to include 16 species of small, dentate, ovateacuminate Afrotropical snails. An identification key is provided and biogeography, anatomy and systematics are discussed. The type species is the Kenyan D. radius (Preston, 1910) comb. nov., whose name has informally been used for part of the group in the past. Substantial intraspecific variation occurs in three species: D. radius itself, D. browni (van Bruggen, 1969) comb. nov. and D. minuscula (Morelet, 1877) comb. nov. (= Ennea fischeriana Morelet, 1881) (non Gulella minuscula Emberton \& Pearce, 2000) . We recognise subspecies within each of these: D.radius radius (Preston, 1910) comb. nov., D. r. calva (Connolly, 1922) comb. et stat. nov., D. browni browni (van Bruggen, 1969) comb. nov., D. b. mafiensis subsp. nov., D. b. semulikiensis subsp. nov., D. minuscula minuscula (Morelet, 1877) comb. nov., D. m. mahorana subsp. nov. Six new Tanzanian species are described: $D$. cresswelli sp. nov., $D$. delta sp. nov., D. ecclesiola sp. nov., D. frontierarum sp. nov., D. minareta sp. nov., and D. pembensis sp. nov. The genus includes seven other previously described species: D. cuspidata (Verdcourt, 1962) comb. nov.; D. rondoensis (Verdcourt, 1994) comb. nov.; D. conoidea (Verdcourt, 1996) comb. nov.; D. selene (van Bruggen \& Van Goethem, 1999) comb. nov.; D. meredithae (van Bruggen, 2000) comb. nov.; D. nictitans (Rowson \& Lange, 2007) comb. nov.; and D. delgada (Muratov, 2010) comb. nov.
\end{abstract}

Key words. Mollusca, Africa, Eastern Arc Mountains, Albertine Rift, biogeography.

Rowson B. \& Tattersfield P. 2013. Revision of Dadagulella gen. nov., the "Gulella radius group" (Gastropoda: Streptaxidae) of the eastern Afrotropics, including six new species and three new subspecies. European Journal of Taxonomy 37: 1-46. http://dx.doi.org/10.5852/ejt.2013.37

\section{Introduction}

The Streptaxidae J. Gray, 1860, or "hunter snails" (Herbert \& Kilburn 2004) are the most speciose terrestrial mollusc family in the Afrotropics. One group of small, ribbed, ovate-acuminate streptaxids, usually with a pointed apex and with characteristic apertural dentition, constitutes a distinctive part of the eastern Afrotropical fauna. They are litter-dwellers in lowland and montane forest and other well-vegetated habitats and can be locally common (e.g. van Bruggen \& Appleton 1977; Rowson et al. 2010b). The species are among those currently included in Gulella L. Pfeiffer, 1856, an extremely large 
genus much in need of revision. Gulella includes several subgenera, some monotypic, erected for the conchologically more characteristic species. However, no such name is available for the group of taxa in question. The group includes those species first referred to by van Bruggen (2000) as the "Gulella radius group", the name being taken from the Kenyan Ennea radius Preston, 1910. The "Gulella radius group" has never been revised, but has been touched upon by Verdcourt $(1962,1985,1996)$, van Bruggen \& Meredith (1984) (who called it the "Gulella browni group"), Tattersfield (1998b), van Bruggen (2000), Rowson (2007a), Rowson \& Lange (2007), Rowson et al. (2010a, b) and Muratov (2010). These authors appear to disagree on the composition of the group. For example, van Bruggen $(1969,2000)$ included the Kenyan G. pretiosa (Preston, 1911), which other authors did not. Muratov (2010) did not mention G. selene van Bruggen \& Van Goethem, 1999, G. meredithae van Bruggen, 2000 or G. nictitans Rowson \& Lange, 2007, three species which were each considered to belong to the "Gulella radius group" by their original authors. Preston (1910) noted the similarity between E. radius and Pupa minuscula Morelet, 1877 of the Comoros, a comparison not drawn by later authors. Verdcourt, meanwhile, did not associate the above named East African species with one another in his checklists $(1983,2006)$. In Richardson's (1988) catalogue, the relevant species are treated in separate genera. There is thus a need to discuss the evidence for the existence of such a group and to define it more precisely. We here delimit it on conchological grounds and describe its key features, including available anatomical and molecular data. All species previously assigned to the "Gulella radius group", with the exception of G. pretiosa (excluded because of sequence and anatomical reasons, see below), are included, as are several others.

A second difficulty is the apparent conchological variability of some species that have been attributed to this group. For example, G. cuspidata Verdcourt, 1962 was distinctive enough to key out first in Verdcourt's (1962) keys to the then known East African Gulella species. However, the other relevant species in the key, G. radius (Preston, 1910) and G. calva Connolly, 1922 key out in not two but three other, separate places despite Verdcourt's (1962) suggestion that one of them is "scarcely more than a variety" of the other. Verdcourt later (1985) speculated whether the group consisted of only a single variable species G. radius, yet maintained G. radius, G. calva and G. cuspidata as distinct in his checklists $(1983,2006)$. He had almost certainly not seen material of most of the species we here recognise as new. We consider most of these to be readily separable from G. radius using the key and other information we provide. In other cases the separation is more difficult and some taxa could be shown to be more closely related to one another as more material becomes available, although we have studied material from many additional populations as well as the relevant types. This appears sufficient to assess intrapopulation variation and to detect examples of species occurring in sympatry without morphological intermediates, at least in Tanzania (two species occur at Pugu, two at Kwamgumi, and three at Kimboza). We also emphasize that, although we intend our taxa to reflect monophyletic lineages, this is a revisionary study and not a phylogenetic one. Further phylogenetic work is necessary to test hypotheses on the age and relationships of the taxa.

\section{Material and Methods}

Type and other material was studied at or on loan from the following museums, or has been deposited with them: National Museum of Wales, Cardiff, UK (NMW); The Natural History Museum, London, UK (NHMUK; was BMNH); Netherlands Centre for Biodiversity Naturalis, Leiden, the Netherlands (RMNH); Royal Museum for Central Africa, Tervuren, Belgium (MRAC); Royal Belgian Institute of Natural Sciences, Brussels, Belgium (RBINS); Senckenberg Forschungsinstitut und Naturmuseum, Frankfurt, Germany (SMF); National Museums of Kenya, Nairobi, Kenya (NMK); National Museum of Tanzania, Dar es Salaam, Tanzania (NMT); and the KwaZulu-Natal Museum, Pietermaritzburg, South Africa (NMSA). Intact adult shells were measured with Vernier callipers and photographed in apertural view with further measurements made using the software ImageJ (Rasband 1997-2011). The number of whorls was counted in this view to the nearest 0.5 whorl. The number of ribs per $\mathrm{mm}$ on the penultimate 
whorl was used as a measure of sculpture because the front of the body whorl was often calloused or eroded smooth. A spire angle was measured as the angle enclosed by a pair of lines beginning at the ends of the upper suture of the penultimate whorl and meeting at the shell apex.

A note on terminology is required. Our preferred term for the overall shell shape of the majority of species, where the maximum width is reached at approximately the middle of the shell (e.g. all of Figs 6-26) is 'ovate-acuminate' (after van Bruggen \& Van Goethem 1999; van Bruggen 2000; Muratov 2010, etc.). In nearly all species of the group the spire is substantially tapered towards the apex. The spire has itself usually been referred to as 'acuminate' (e.g. Preston 1910; Verdcourt 1962; van Bruggen \& Van Goethem 1997; Muratov 2010). The sides of the upper whorls of the spire appear concave in a number of species (e.g. Figs 29-31) for which our preferred term is 'coeloconoid'. Where the upper whorls of the spire appear convex we use the term 'cyrtoconoid'. The apex of the shell, i.e. that part of the spire formed by the embryonic whorls, is pointed in most species, sharply in some. In others it is rounded at a macroscopic scale (any point is of course actually rounded at the most microscopic of scales). This variation appears to be at least partly independent of the spire angle, e.g. Figs 33-34 have a similar spire angle but very different apices.

For dimensions, see Table 1.

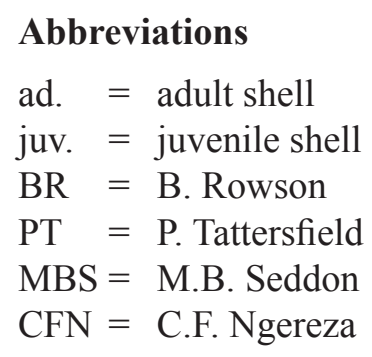

\section{Results}

Order Stylommatophora Schmidt, 1855

Superfamily Streptaxoidea J. Gray, 1860

Family Streptaxidae J. Gray, 1860

Genus Dadagulella gen. nov. urn:1sid:zoobank.org:act:1C3959C3-50E5-4DFF-A5AC-67BB9F05A042

Figs 1-84; Table 1

\section{Type species}

Ennea radius Preston, 1910.

\section{Included species}

Sixteen. In addition, D. radius (Preston, 1910) comb. nov. and D. minuscula (Morelet,1877) comb. nov. are treated as having two subspecies and D. browni (van Bruggen, 1969) comb. nov. as having three (see below).

\section{Diagnosis}

Shell small (2.3-5.5 $\mathrm{mm}$ high), ovate to ovate-acuminate with an acuminate (sometimes coeloconoid or cyrtoconoid) spire; strongly and often sinuously radially ribbed, never smooth. Peristome reflected. Aperture dentate, with at least one parietal and one palatal tooth. Juvenile aperture (known from 7-8 species) dentate (except possibly in D. nictitans comb. nov.), aperture not downturned. Radula 


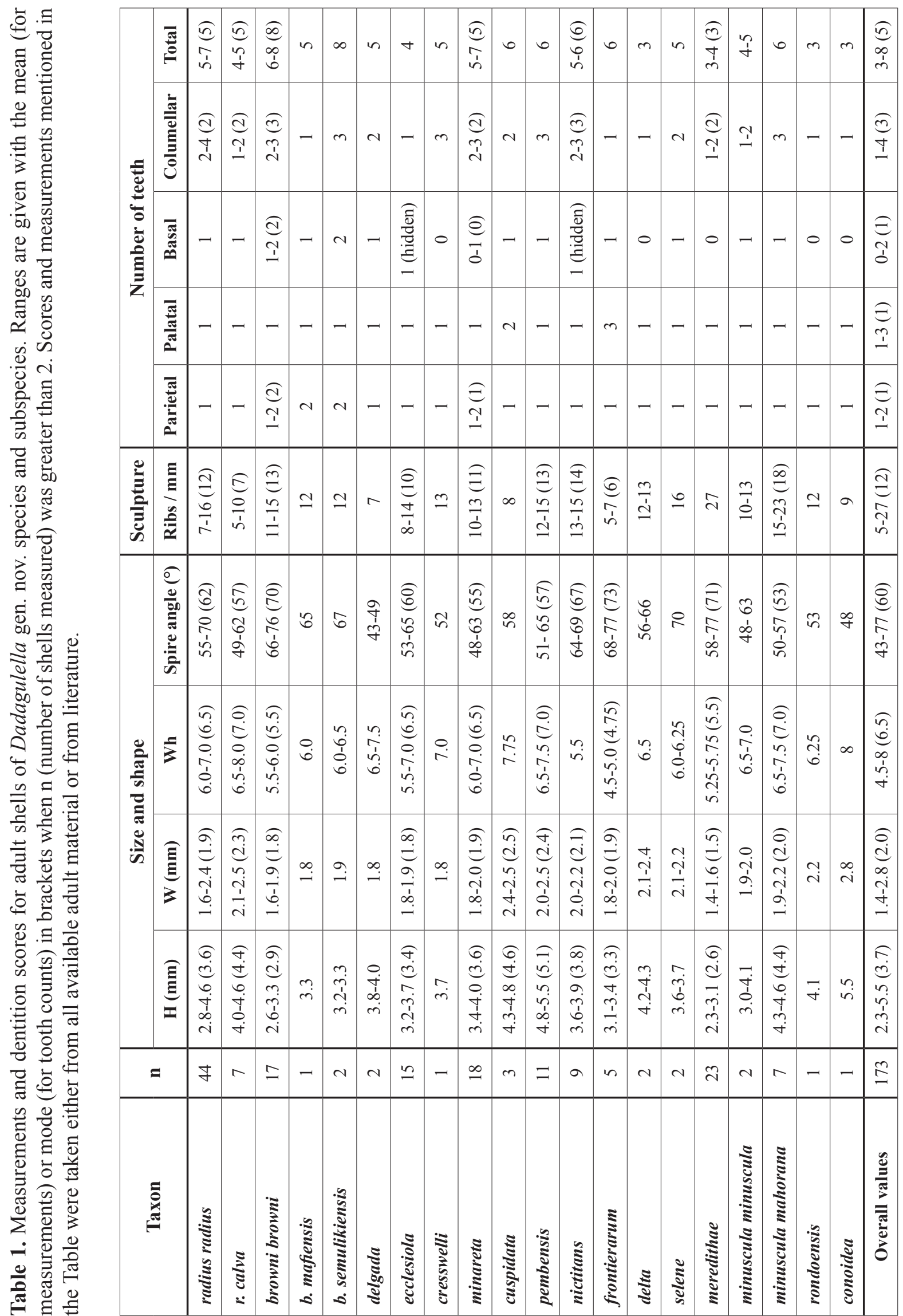


(known from three species) bearing multicuspid teeth, the outer cusps much smaller than the inner. Other anatomy (known from six species): salivary gland bilobed or Y-shaped. Vas deferens thickened or with diverticulum prior to insertion on penis, penis lacking sheath, with a muscular apex in which is embedded a spatulate scoop with a microscopically serrated tip, usually associated with one or two large apical hooks, and a few $(<40)$ smaller hooks lower down. For dimensions, see Table 1.

\section{Etymology}

Prefix from Swahili noun " $d a d a$ " meaning sister, with reference to the apparent relationships and East African centre of diversity of the group.

\section{Description}

SHELl (Figs 1-64). Small to medium-sized relative to species of Gulella (2.3-5.5 mm high x 1.4-2.8 mm wide), of 4.5-8 whorls. Ovate to ovate-acuminate (maximum width being approximately at middle of shell, usually at penultimate whorl) or subconical (maximum width being in bottom third of the shell, at body whorl). Spire characteristically narrowly to broadly acuminate, occasionally coeloconoid or cyrtoconoid (spire angle $43-77^{\circ}$ ), angle varying a little within most species. Apex (i.e. top of spire) pointed in most species, but rounded in others. Sutures usually deep, shells never completely smoothsided. Umbilicus closed or narrowly open, this sometimes varying within a species. Embryonic whorls usually smoothly granulate, with fine radial striae in two species, or irregularly punctate in another. The last part of the embryonic shell is sculptured with very fine radial striae in most (possibly all) species but these are worn away in all but the freshest individuals. Later whorls never smooth, with radial ribs (5-27 per mm on penultimate whorl) running from suture to suture, often strong and/or sinuous, lamella-like in some species. Peristome complete, or incomplete parietally, always reflected to some extent. Outer palatal surface of aperture with a depression, sometimes furrow-like, corresponding to the palatal tooth, and sometimes another corresponding to the basal tooth. Dentition 3-fold (rarely, and debatably, 2-fold) to 8-fold. Dentition consisting of at least one parietal tooth and one palatal tooth, the latter often slablike and/or bifid, sometimes forming a parieto-palatal sinus. Usually also with one deep-set columellar baffle, folded or sub-bifid or sub-trifid in some species. Often with additional parietal, palatal, basal and/or columellar teeth or denticles. Dentition is variable in some species but the form, as well as the number, of the teeth is often consistent enough to distinguish species. Juvenile shells (known from 7-8 species) always with 3-fold to 4-fold apertural dentition (Figs 43-50) except in one species, D. nictitans comb. nov., where the only known juvenile has no teeth. In several species, some or all of the teeth in juvenile shells appear to be resorbed at intervals.

Cephalopodium. Pale cream or yellow, usually with apricot-coloured to orange tentacle retractors and sometimes with brown speckles on the mantle.

Pallial complex. Sigmurethrous, with long zone of contact between long, oblong kidney and hindgut, pulmonary cavity not strongly vascularised.

Salivary GLANDS (Figs 69-72). United, soft, not tumid, elongate, bilobed to Y-shaped; each duct leaving at the apex of the lobe and evenly thick throughout.

Buccal MASs. Very small and elongate, radula correspondingly small, tightly enrolled and difficult to locate or prepare.

RaDULA (Figs 65-68). (known from three species) With a unicuspid central tooth and 9-15 laterals in each half-row, diminishing gradually in size laterally. Most or all laterals distinctively bicuspid or multicuspid, with outer cusps smaller or much smaller than inner cusps. Teeth are somewhat delicate (or flexible; Aiken 1981) and are short and flake-like at the ventral end of the radular ribbon. 
Genitalia. (Figs 73-83) (known from six species) Hermaphroditic duct diverticulum (talon) short, large, sausage-shaped, not convoluted. Bursa copulatrix attending albumen gland. Acini of prostate indistinct to distinct. Vagina attenuate. Oviduct often containing a single large egg. Vas deferens either thickened prior to insertion on penis, or appearing as such but actually with a diverticulum lying parallel to it. Vas deferens entering penis subapically. Penial retractor muscle branching off columellar muscle, attaching partly to vas deferens, thus sometimes bifid or nearly so. Penis elongate, tubular. Penial sheath absent, but lower part sometimes surrounded by a thin sheath-like layer contiguous with walls of lower penis. Interior of penis with weak radial pilasters and small rhombic pads, sometimes with a longitudinal pilaster or short rounded lobe. Apical part of penis with a spatulate or broad "scoop". One end with a microscopically serrated tip, the other end deeply embedded in muscular apex of penis. Scoop usually associated with one or two large, broad hooks, lying just behind or underneath it. Scoop and hook(s) could conceivably act together as a grip or pincer. Elsewhere in penis, a longitudinal row or group of few $(<40)$ short, simple hooks mounted on rhombic pads. "Spermatophore" (see Discussion) detected in two species: comma-shaped, lying with reservoir in vagina with longitudinally ribbed tail extending into mid penis. End of tail probably originally weakly attached to wall of penis [as in one specimen of D. radius radius (Preston, 1910) comb. nov.] but subsequently detached. Partially digested tail fragments present in bursa of one specimen of $D$. pembensis sp. nov.

\section{Known distribution}

Eastern Kenya, eastern Tanzania, western Uganda, eastern DR Congo, Malawi, eastern Zambia, Mozambique, north-eastern South Africa, Comoros archipelago (Fig. 84).

\section{Gender}

Feminine.

\section{Comparison and remarks}

See General Discussion.

Dadagulella radius radius (Preston, 1910) comb. nov.

Figs 1-5, 9-20, 43-45, 52-53, 65, 69, 73, 77-78, 83-84; Table 1

Ennea radius Preston, 1910: 529, pl. VII, fig. 8.

Gulella radius - Verdcourt 1962: 13, 17, ? not 22 (see D. radius calva below). - van Bruggen 1969: 71. —Verdcourt 1983: 234; 1985: 119, fig. 17; 1996: 136. — Tattersfield 1998a: 83; 1998b: 37. — Verdcourt 2000: 415. — van Bruggen 2000: 233. — Lange \& Mwinzi 2003: 64-66. — Verdcourt 2006: 48. - Rowson 2007a: 441-442, fig. 56 (not fig. 54). - Rowson \& Lange 2007: 31. - Muratov 2010: 277. — Rowson et al. 2010b: 28-29, in part. — Ndalila 2011: 24.

Ennea radius - Richardson 1988: 26.

\section{Type material examined}

KENYA: lectotype (here designated) MRAC.I17592: 1 ad., "Shimbi Hills, British East Africa", standing as "radius", labelled "ex Putzeys-Musée, 1935", "type" and apparently the shell figured in Preston (1910: pl. VII, fig. 8). Verdcourt (1985) wrote that a second shell from Shimbi in the NHMUK type collection could not be located at that time. We too failed to trace this specimen. Van Bruggen (1969) referred to two other NHMUK shells from Gazi as "paratypes", presumably because they were labelled as such. However, Gazi $\left(4.42^{\circ} \mathrm{S}, 39.50^{\circ} \mathrm{E}\right)$ is around $30 \mathrm{~km}$ from the type locality of Shimbi (Shimba) Hills $\left(4.25^{\circ} \mathrm{S}, 39.38^{\circ} \mathrm{E}\right)$, and Preston (1910) distinguished between the two localities elsewhere in his paper. Thus it cannot be assumed that Gazi material has type status. 


\section{Other material examined}

KENYA: NMW.1955.158.25050: 3 ads, 7 juvs, Gazi, standing as "radius". RMNH.MOL.273272: 1 ad., Gazi, standing as "radius". RMNH.MOL.273826: 1 ad., near Mombasa (approx. $4.04^{\circ} \mathrm{S}, 39.66^{\circ} \mathrm{E}$ ), amongst river debris, Sep. 1987. NMW.Z.1990.067.00001: 1 ad., Arabuko-Sokoke Forest $\left(3.32^{\circ} \mathrm{S}\right.$, $\left.39.87^{\circ} \mathrm{E}\right), 20 \mathrm{~km} \mathrm{SW}$ of Gedi, Brachystegia Benth. woodland on sandy soil with some leaf litter, leg. MBS, 12 Aug. 1989. NMW.Z.2012.042.00002: 2 ad., Diani Beach $\left(4.27^{\circ} \mathrm{S}, 39.59^{\circ} \mathrm{E}\right)$, south of Mombasa, under deep mixed broadleaf litter, 18 m alt., leg. P. L. Cresswell, 24 Apr. 1997. NHMUK.1911.10.12.146-147: 2 ads, Gazi, standing as "radius".

TANZANIA: NMW.Z.2009.013.00226: 2 ads, Jozani Forest Reserve $\left(6.23^{\circ} \mathrm{S}, 39.42^{\circ} \mathrm{E}\right)$, Unguja I., Zanzibar, leg. BR, B.H. Warren, \& CFN, 5 Feb. 2009. NMW.Z.2004.014.00023: 10 ads, 1 juv., several

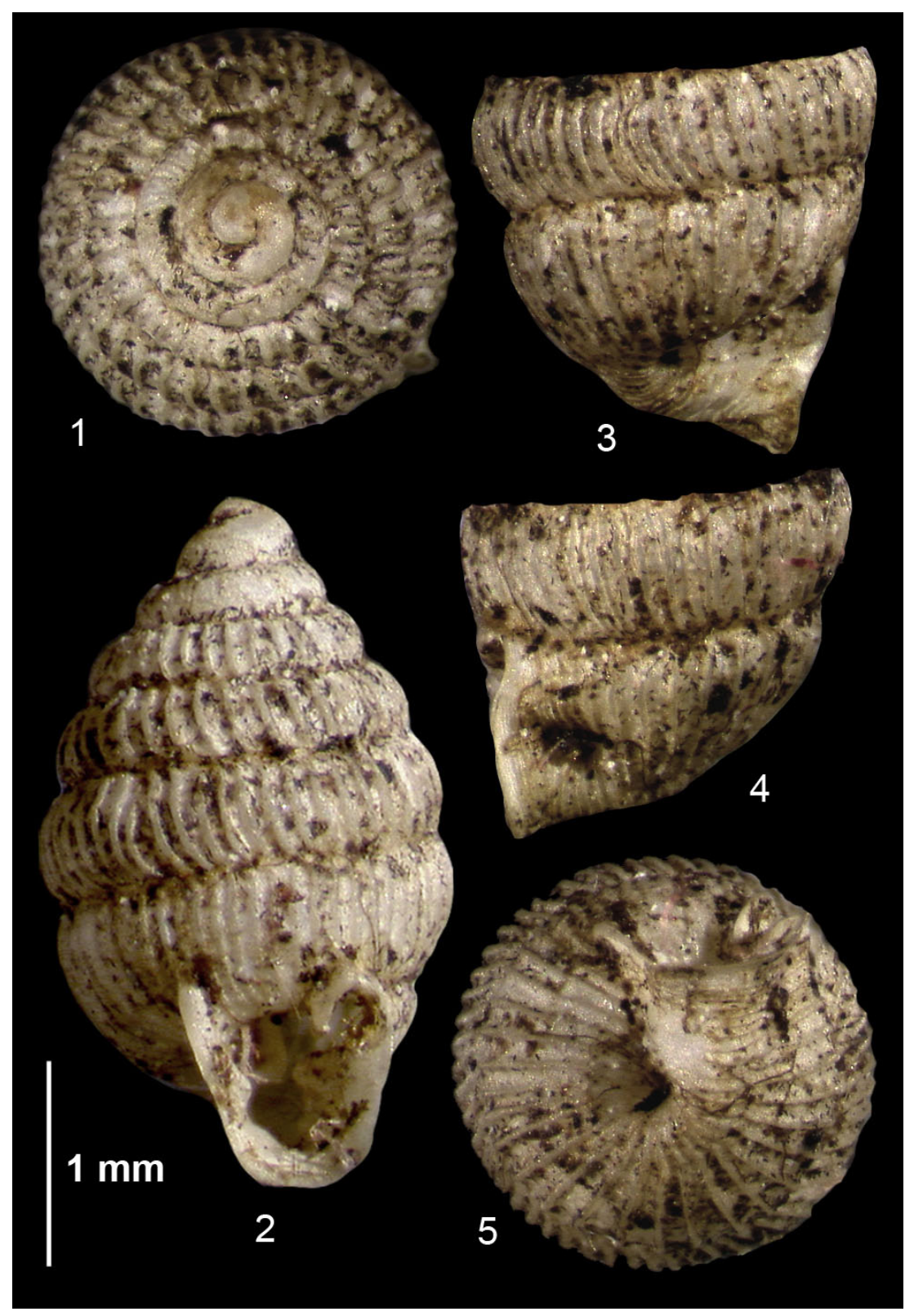

Figs 1-5. Lectotype of Ennea radius Preston, 1910, type species of Dadagulella gen. nov. 1. Apical view. 2. Apertural view. 3. Last two whorls, from left side. 4. Last two whorls, from right side. 5. Umbilical view. 
in poor condition, Jozani Forest Reserve, Unguja I., Zanzibar, leg. PT, MBS, \& CFN, 11-12 Mar. 2000. NMW.Z.2003.001.00006: 2 ads, Mkungwe Forest Reserve (6.90 $\left.\mathrm{S}, 37.91^{\circ} \mathrm{E}\right)$, Uluguru Mts, Morogoro District, submontane forest, approx. $900 \mathrm{~m}$ alt., leg. BR \& CFN, 7 Feb. 2003. NMW.Z.2003.001.00007: 1 ad., 1 juv., Kimboza Forest Reserve $\left(7.01^{\circ} \mathrm{S}, 37.78^{\circ} \mathrm{E}\right)$, Uluguru Mts, Morogoro District, lowland forest on limestone, approx. 300 m alt., leg. BR, PT, MBS, \& CFN, 5 Feb. 2003. NMW.Z.2007.012.00001: 1 ad., Pugu Hills Nature Reserve (6.89 $\left.{ }^{\circ} \mathrm{S}, 39.09^{\circ} \mathrm{E}\right)$, SE of Dar es Salaam, leg. CFN, Jan. 2007 (sequenced by Rowson et al. 2010a as "Gulella radius"). NMT.2000/0130: 6 ads, 6 juvs Mbudya I. (6.66 ${ }^{\circ}$ S, 39.25E), Dar es Salaam, leg. CFN \& NMT team, 14 May 1998. NMW.Z.1995.016.00005: 3 ads, Kiono Forest $\left(6.15^{\circ} \mathrm{S}, 38.59^{\circ} \mathrm{E}\right)$, NW of Dar es Salaam (site III), leg. PT, 5 Mar. 1995. NMW.Z.1995.016.00006: 1 ad., Pugu, S of Dar es Salaam (site II), leg. PT, 6 Mar. 1995. NMW.Z.1995.016.00007: 2 ads, Pugu Forest, S of Dar es Salaam (site I), leg. PT, 6 Mar. 1995. NMW.Z.1995.016.00008: 1 ad., Amboni caves and Mkulumuzi Gorge $\left(5.06^{\circ} \mathrm{S}, 39.05^{\circ} \mathrm{E}\right)$, near Tanga (site I), leg. PT, 3 Mar. 1995. NMW.Z.1995.016.00010: 3 ads, 2 juvs, Amboni, near Tanga (site I), leg. PT, 3 Mar. 1995. NMW.Z.1995.016.00009: 2 ads, Amboni, near Tanga (site III), leg. PT, 3 Mar. 1995. NMW.Z.1995.016.00011: 6 ads, Amboni, near Tanga (site II), leg. PT, 3 Mar. 1995. NMW.Z.2003.074.00005: 1 ad., Kwamgumi Forest Reserve (4.94 $\left.{ }^{\circ} \mathrm{S}, 38.75^{\circ} \mathrm{E}\right)$, East Usambara Mts, Muheza District, lowland forest at approx. $350 \mathrm{~m}$ alt., leg. Frontier Tanzania, 4 Dec. 1996. NMW.Z. 2003.074.00006: 1 ad. in poor condition, Mtai Forest Reserve $\left(4.87^{\circ} \mathrm{S}, 38.77^{\circ} \mathrm{E}\right)$, East Usambara Mts, Muheza District (plot 73), riverine forest at $200 \mathrm{~m}$ alt., leg. Frontier Tanzania, 23 Jan. 1996.

\section{Description}

Shell (Figs 1-5, 9-20, 43-50, 52-53). Very variable in size, shape and dentition, small to large (2.80$4.60 \mathrm{~mm}$ high x 1.60-2.44 mm wide), of 6.0-7.0 whorls. Ovate-acuminate, spire narrowly to broadly acuminate (spire angle 55-70 $)$. Apex pointed. Embryonic whorls smoothly granulate. Later whorls with relatively coarse and few ribs (7-16 per $\mathrm{mm}$ on penultimate whorl). Sutures relatively deep. Umbilicus closed or narrowly open. Peristome complete or (more often) incomplete parietally. Outer palatal surface of aperture with a depression corresponding to the palatal tooth and sometimes another one corresponding to the basal tooth. Dentition 5-fold to 7-fold, consisting of at least: one lamella-like parietal tooth; one slab-like palatal tooth, often bifid; one basal denticle; one shallow columellar denticle (very weak in some cases) and one deep-set columellar baffle, always visible. Parieto-palatal sinus, if present, broad, seldom narrow or parallel-sided. Neither the columellar baffle nor basal denticle were mentioned in Preston's (1910) original description, although both are clearly visible on the lectotype which is apparently the originally figured specimen. We assume this to have been a lapsus. One or two additional columellar denticles may be present (e.g. Figs 12, 14, 15). Juvenile shells (Figs 43-45) with 3-fold dentition: one parietal lamella; one bifid basal tooth; and one columellar tooth or thickening. Some earlier teeth are retained in some juveniles and even adults (e.g. some specimens from Jozani).

Cephalopodium. Pale cream or yellow, with apricot to orange tentacle retractors and often with brown speckles on the mantle.

Salivary GLANDS (Fig. 69). United, soft, not tumid, elongate, bilobed to nearly Y-shaped; each duct leaving at the whitened apex of the lobe and evenly thick throughout.

RADULA (Fig. 65). With a unicuspid central tooth and around 13 laterals in each half-row, diminishing gradually in size laterally. All laterals bicuspid or tricuspid, with outer cusps much smaller than inner cusps.

Genitalia (Figs 73, 77, 83). Vas deferens appearing thickened prior to insertion on penis but actually with a short, broad parallel diverticulum. Penial sheath absent but with a thin sheath-like layer contiguous with walls of lower penis. Interior of penis with weak radial pilasters and small rhombic pads, sometimes 
with a longitudinal pilaster or short, rounded and weakly chitinized lobe. Apical, muscular part of penis with a single large hook, associated with a "scoop" with microscopically serrated tip. Elsewhere in penis, a single longitudinal row of short, simple hooks mounted on rhombic pads. "Spermatophore" (see Discussion) present in penis and vagina of one Amboni specimen; "spermatophore" tail, apparently attached to penis wall, present in penis of one Pugu specimen.

\section{Range and habitat}

Eastern Kenya and eastern Tanzania, including Unguja (Zanzibar) island. Apparently replaced by other Dadagulella gen. nov. species on Pemba island and in some lowland areas and montane forests, and by D. browni comb. nov. s.l. in Tanzania from around $7.8^{\circ} \mathrm{S}$ southwards. Dadagulella r. radius comb. nov. is sympatric with other Dadagulella gen. nov. species at Kwamgumi, Pugu and Kimboza [it has also been recorded from Kimboza by Verdcourt (2006: 48)]. The records are mainly from forest and other wellvegetated habitats; Verdcourt (2000) suggested the habitat was "woodland/forest". Lange \& Mwinzi (2003) found D. radius comb. nov. across several forest types at Arabuko-Sokoke, but Ndalila (2011) found only three specimens in the Shimba Hills, all in scrub and grassland rather than forest.

\section{Remarks}

This appears to be the most widespread and variable species of Dadagulella gen. nov. In this we concur with van Bruggen (1969) and Verdcourt (1985) that D. radius comb. nov. is a species variable enough to include shells as different as the lectotype (Figs 1-5,11) and those from Diani Beach (Fig. 14). We retain one such extreme form, subsequently described by Connolly (1922) as Gulella calva Connolly, 1922, as a subspecies of $D$. radius comb. nov. (see below) but we refrain from describing additional subspecies since these forms are not obviously geographically isolated (e.g. at Amboni, Fig. 15) and occur throughout the geographical range of the species. The variation between them often appears continuous rather than discrete (e.g. compare Figs 17-20, each from a similar latitude and arranged in order from $\mathrm{W}$ to E). Furthermore, some variability is often present at a single locality, e.g. at Gazi (compare Figs 12 and 13). Despite this, D. radius comb. nov. s.l. differs from other similar, lowland species as follows. It differs from D. browni comb. nov. s.l. in never having either an additional parietal denticle or two basal denticles, and in normally having a broader (or no) parieto-palatal sinus. It differs from D. delgada (Muratov, 2010) comb. nov. in lacking the flaring, lamella-like ribs and nearly always having a more broadly acuminate spire. It differs from $D$. ecclesiola sp. nov. in not having the basal denticle hidden behind the palatal tooth, in having at least one shallow columellar tooth, and in having a broader (or no) parieto-palatal sinus. The distinction between D. radius comb. nov. s.l. and D. minuscula comb. nov. of the Comoros, with which it was compared by Preston (1910), is discussed under the latter species.

Dadagulella radius calva (Connolly, 1922) comb. et stat. nov. Figs 6-8, 51, 84; Table 1

Gulella calva Connolly, 1922: 495, pl. XIV, fig. 35.

Gulella calva-Verdcourt 1962: 17; 1983: 234. — Richardson 1988: 62. — Verdcourt 2000: 215; 2006: 49. ? "Gulella radius (Preston) var. (K, Mrima Hill Forest)" - Verdcourt 1962: 22.

\section{Type material examined}

KENYA: lectotype (here designated) NHMUK.1937.12.30.486: 1 ad., Taru Desert (i.e. a semi-arid area of southeastern Kenya now partly in the Tsavo East National Park, approx. $3.40^{\circ} \mathrm{S}, 39.00^{\circ} \mathrm{E}$ ), leg. Percival, labelled "type", and apparently the shell figured in Connolly (1922: pl. XIV, fig. 35). 


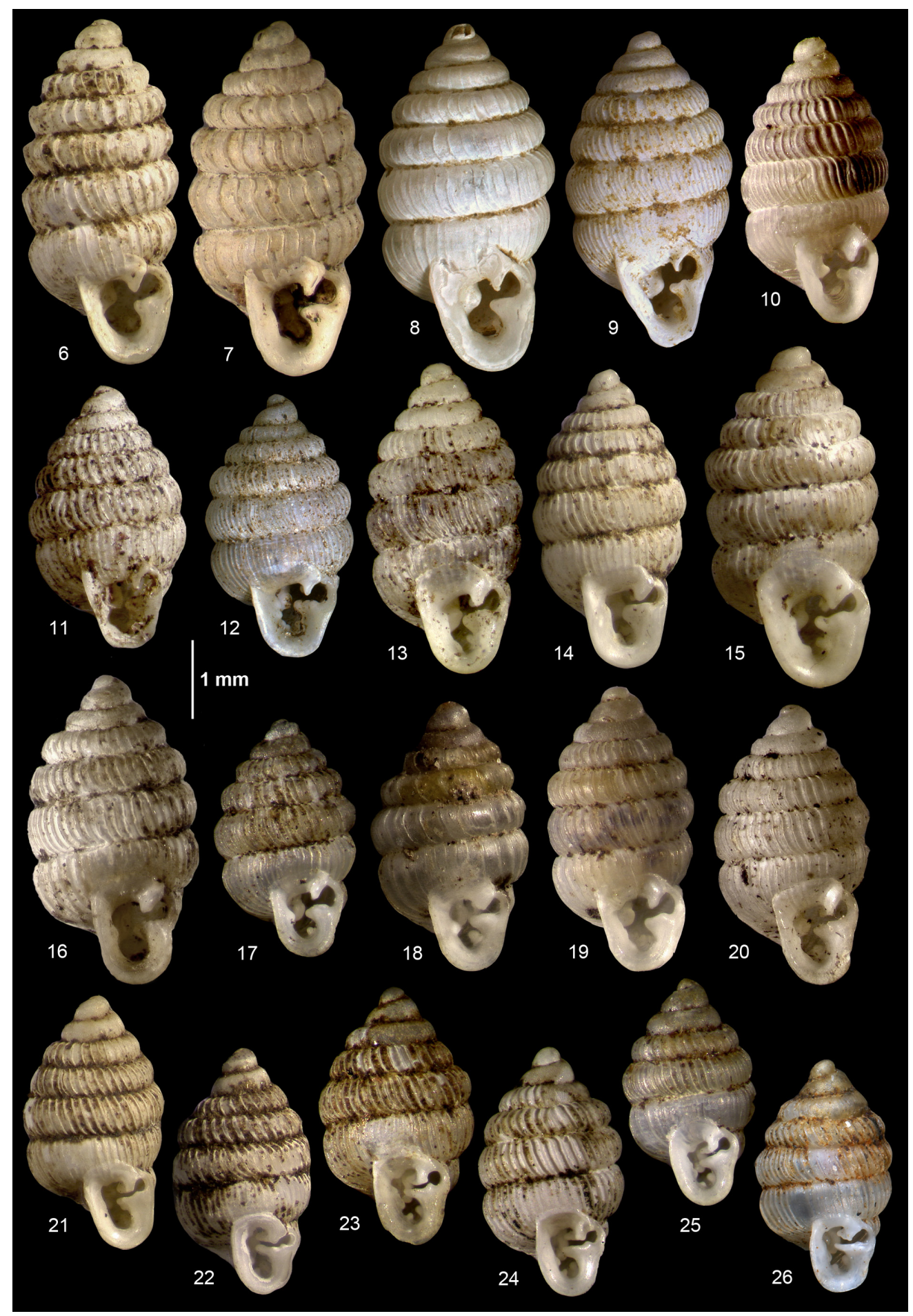

Figs 6-26. Adult shells of Dadagulella radius (Preston, 1910) comb. nov., D. browni (van Bruggen, 1969) comb. nov. and their respective subspecies. 6-20. D. radius comb. nov. s.l. 6-8. D. radius calva (Connolly, 1922): 6. Lectotype, Taru Desert. 7. Taru Desert near Malindi. 8. Near Mombasa. 9-20. D. radius radius: 11. Lectotype, Shimba Hills. 12. Gazi. 13. also Gazi. 14. Diani Beach. 15. Amboni. 16. Kimboza. 17. Mkungwe. 18. Pugu. 19. Mbudya I. 20. Jozani. 21-26. D. browni comb. nov. s.l.: 21. D. browni mafiensis subsp. nov., holotype, Mlula. 22. D. browni semulikiensis subsp. nov., holotype, Semuliki NP. 23-26. D. browni browni: 23. Mwanihana. 24. Mzelezi. 25. Pomene Bay. 26. Holotype, Lake Sibayi (after van Bruggen 1969). 


\section{Other material examined}

KENYA: NMW.1955.158.25052: 5 ads, “ca. lat. $3^{\circ} 5^{\prime}$, long. 39²7”, standing as "calva Co." and later labelled "cf. radius" by B. Verdcourt. Assuming that the latitude refers to a point south rather than north of the equator, the coordinates correspond to a point in the Taru Desert, $\pm 75 \mathrm{~km}$ inland of Malindi. RMNH.MOL.288087: 1 ad., near Mombasa (approx. 4.04º S , 39.66º E), amongst river debris, Sep. 1987.

\section{Description}

Shell (Figs 6-8, 51). Large (4.00-4.60 mm high x 2.10-2.50 mm wide), of 6.5-8.0 whorls. Ovateacuminate, but more columnar than other Dadagulella gen. nov., spire narrowly to broadly acuminate (spire angle $49-62^{\circ}$ ). Apex pointed. Embryonic whorls smoothly granulate. Later whorls with characteristically coarse, few and widely spaced ribs (5-10 per mm on penultimate whorl). Sutures deep. Umbilicus closed or nearly so. Peristome incomplete parietally. Outer palatal surface of aperture with a depression corresponding to the palatal tooth. Dentition characteristically simple, 4-fold to 5-fold, consisting of: one lamella-like parietal tooth; one slab-like palatal tooth without parieto-palatal sinus; one basal denticle; and one deep-set columellar baffle, always visible, sometimes with a very slight, shallower columellar tooth. Juvenile shells and anatomy unknown.

\section{Range and habitat}

Lowlands of extreme southeastern Kenya, including Taru Desert. This subspecies has also been recorded from Malindi (Verdcourt 1962: 17) and Mrima Hill (4.48 $\left.{ }^{\circ} \mathrm{S}, 39.25^{\circ} \mathrm{E}\right)$ (Verdcourt 2006). Verdcourt (2000) suggested the habitat was "bushland to forest", in contrast to "woodland/forest" for D. r. radius comb. nov. Shells of both D. r. radius comb. nov. and D. r. calva comb. et stat. nov. have been found in river debris near Mombasa, but may have been washed in from different localities.

\section{Remarks}

The lectotype and similar material of this subspecies (Figs 6-8, 51) differ from D. r. radius comb. nov. in the more widely spaced ribs, more columnar shape and simpler dentition, although some specimens seem to show intermediate characters. Verdcourt evidently had difficulty separating them. Although Verdcourt (1962: 17) suggested G. calva was "scarcely more than a variety of G. radius", it keyed out in a separate part of his key, with radius appearing in two other places $(1962: 13,22)$. The second of these (p.22) was listed as "Gulella radius (Preston) var. (K [Kenya], Mrima Hill Forest)". Verdcourt's measurements, description, and range of apertural tooth formulas allow attribution of this taxon to $D . r$. calva comb. et stat. nov.. In his later checklists, Verdcourt (1983: 234; 2006: 48-49) maintained the two as separate species, and gave Mrima Hill as a locality for calva but not radius. He also kept them apart in his list of coastal molluscs (2000). Thus it appears likely that he later decided that (1962: 22) "radius var." belonged to what we treat as $D$. r. calva comb. et stat. nov. and not to what we treat as D. r. radius comb. nov. It also appears that he decided not to separate the two taxa. We too found this a difficult decision to take, owing to the morphological, habitat and distributional differences, which may of course be interrelated. To acknowledge this difficulty, and the potential difficulties in assigning future material to either, we rank calva as a subspecies of radius.

Dadagulella browni browni (van Bruggen, 1969) comb. nov. Figs 23-26, 47-48, 71, 74, 82, 84; Table 1

Gulella browni van Bruggen, 1969: 69-71, figs 25-26.

Gulella browni - van Bruggen \& Appleton 1977: 31-32. — Aiken 1981: 321-323, fig. 5. — Richardson 1988: 60. — Verdcourt 1990: 349. — van Bruggen \& Van Goethem 1999: 40. — van Bruggen 2000: 233-234. — Herbert \& Kilburn 2004: 212. — Rowson \& Lange 2007: 31. — Muratov 2010: 277. 
"a closely related species from Zululand" - Verdcourt 1985: 119.

Gulella cf. radius - Tattersfield et al. 2006: 52, 54, 58.

\section{Type material examined}

SOUTH AFRICA: holotype RMNH.MOL.54894: 1 ad., Lake Sibayi (approx. 27.34으, 32.71 ${ }^{\circ} \mathrm{E}$ ), KwaZulu-Natal, dune forest on the east shore, leg. D.S. Brown, 12 Jun. 1966 (examined digital photograph only).

\section{Other material examined}

TANZANIA: NMW.Z.2003.001.00008: 6 ads, 5 juvs, Mt. Mwanihana Forest Reserve $\left(7.82^{\circ} \mathrm{S}\right.$, $36.83^{\circ} \mathrm{E}$ ), Udzungwa Mts National Park, Kilombero District, lowland forest at approx. 600-900 m alt., leg. BR, PT, MBS \& CFN, 29 Jan. 2003. NMW.Z.2003.001.00009: 4 ads, data as previous but $700 \mathrm{~m}$ alt. NMW.Z.1997.007.00003: 5 ads, 2 juvs, Mzelezi Forest Reserve $\left(8.79^{\circ} \mathrm{S}, 36.72^{\circ} \mathrm{E}\right)$, Mahenge Mts, Ulanga District, forest on limestone, approx. $645 \mathrm{~m}$ alt., leg. PT, MBS \& CFN, 6 Feb. 1997. NMW.Z.1997.007.00004: 1 ad., data as previous. NMW.Z.1997.007.00005: 2 ads, 6 juvs, data as previous.

MOZAMBIQUE: NMW.Z.2012.040.00001: 2 ads, Pomene Bay, Inhambane Province, near lighthouse $\mathrm{S}$ of old hotel $\left(22.9417^{\circ} \mathrm{S}, 35.5913^{\circ} \mathrm{E}\right.$ ), degraded dune forest, in leaf-litter, leg. D. Herbert, Oct. 2002 (ex NMSA.L5797). NMSA.L5797: 2 ads, data as previous.

SOUTH AFRICA: NMW.Z. 2012.040.00002: 3 ads, Kosi Bay mouth, KwaZulu-Natal $\left(26.89^{\circ} \mathrm{S}\right.$, $32.88^{\circ} \mathrm{E}$ ), dune forest, in sandy leaf-litter, leg. D. Herbert \& L. Davis, "11-41”, 13 Oct. 2011 (ex NMSA. W8517). NHMUK.20110173: 2 ads, Lake Sibaya area of Tongaland (approx. 27.35 ${ }^{\circ} \mathrm{S}, 32.67^{\circ} \mathrm{E}$ ), Zululand, S. Africa, leg. C.C. Appleton, Dec. 1972-Nov. 1973.

\section{Description}

SHell (Figs 23-26, 47-48). Small (2.60-3.20 mm high x 1.60-1.90 mm wide), of 5.5-6.0 whorls. Ovateacuminate, spire broadly acuminate (spire angle $66-76^{\circ}$ ). Apex pointed. Embryonic whorls smoothly granulate. Later whorls with relatively coarse ribs (11-15 per mm on penultimate whorl). Sutures relatively shallow. Umbilicus closed or narrowly open. Peristome incomplete parietally. Outer palatal surface of aperture with a depression corresponding to the palatal tooth and another much weaker one corresponding to the basal tooth. Dentition 7-fold to 8-fold, consisting of: one lamella-like parietal tooth and (almost always) one additional parietal denticle; one slab-like palatal tooth, forming a narrow parieto-palatal sinus; two basal denticles; a deep-set columellar baffle, sometimes folded, and one or two shallower columellar denticles. Dentition of 8-fold individuals alternatively recognisable as 7-fold, depending on the interpretation of the columellar and parietal denticles (van Bruggen 1969). Juvenile shells of D. browni comb. nov. were not known to van Bruggen $(1969,2000)$. Herbert \& Kilburn (2004) describe them simply as dentate, but with dentition different from that of the adult. Juveniles from southern Tanzania (Figs 47-48) have dentition similar to, but weaker than, juveniles of D. r. radius comb. nov. (Figs 43-45).

Cephalopodium. Pale cream, with pink-orange tentacle retractors and a few purple-brown speckles in the mantle.

SALIVARY GLANDS (Fig. 71). United, soft, not tumid, elongate, bilobed; each duct leaving at the whitened apex of the lobe and evenly thick throughout.

RADULA. Described and figured by Aiken (1981) as having a unicuspid, 'heart-shaped' central tooth and nine laterals in each half-row, of which at least the inner six are tricuspid, diminishing gradually in size laterally. The outer cusps of most teeth are smaller than the inner cusp. According to Aiken (1981) the teeth are flexible when pressed by a cover slip and there are 47 rows. 
Genitalia (Figs 74, 82). Upper parts of spermoviduct not recovered. Vas deferens appearing thickened prior to insertion on penis but actually with a very short, broad parallel diverticulum. Penial sheath absent. Interior of penis with weak radial pilasters. Apical, muscular part of penis with a single large hook, associated with a spatulate "scoop" with microscopically serrated tip. Elsewhere in penis, a single longitudinal row of short, simple hooks.

\section{Range and habitat}

Coast of north-eastern South Africa: dune forest, coastal forest and bush; also central Mozambique: high forest in Chiluvo [Xiluvo] hills $\left(19.24^{\circ} \mathrm{S}, 34.06^{\circ} \mathrm{E}\right.$ ) at $700 \mathrm{ft}$ (approx. $213 \mathrm{~m}$ ) elevation (van Bruggen 1969; van Bruggen \& Appleton 1977; Herbert \& Kilburn 2004). Also in lowland forest, up to 900 m, in southern Tanzania, as far north as $7.8^{\circ} \mathrm{S}$.

\section{Remarks}

We agree with van Bruggen (1969) that the complex dentition of D. browni comb. nov. s.l. separates it from D. radius comb. nov. s.l., which never seems to have 8 -fold dentition, in particular the extra parietal and basal denticles. The shells of $D$. browni comb. nov. s.l. are also much smaller, less elongate (i.e. have a lower height/width ratio), and have a much narrower and more horizontal parieto-palatal sinus than is usual for D. radius comb. nov. s.l. Although some specimens of D. r. radius comb. nov. approach $D$. browni comb. nov. s.l. in one or more of these respects (e.g. Figs 10, 14, 17) all can be readily assigned to one or the other and the type specimens are morphologically quite different (Figs 1-5, 11, 52 vs. Fig. 26). Material intermediate between D. browni comb. nov. and D. radius comb. nov. might be expected in the intervening area of southern Tanzania or northern Mozambique. However, all the relevant southern Tanzanian material here (e.g. from Mafia and Mahenge) is closer to D. browni comb. nov. s.l. in dentition and other aspects. A recent survey in northern Mozambique (Muratov 2010) encountered only $D$. delgada comb. nov.

Dadagulella browni mafiensis subsp. nov.

Figs 21, 54, 84; Table 1

\section{Etymology}

From Mafia Island, with the final 'a' elided for euphony.

\section{Type material examined}

NHMUK.20110174: 1 ad., Mlula, Mafia I. (approx. $7.87^{\circ} \mathrm{S}, 39.76^{\circ} \mathrm{E}$ ), evergreen coastal thicket on clay loam coral rag, leg. Frontier Tanzania, Oct.-Nov. 1990, labelled "Gulella radius aggreg." by B. Verdcourt.

\section{Other material examined}

None.

\section{Description}

SHell (Figs 21, 54). Small (3.30 mm high x $1.80 \mathrm{~mm}$ wide), of 6.0 whorls. Ovate-acuminate, spire broadly acuminate (spire angle $65^{\circ}$ ). Apex conical. Embryonic whorls smoothly granulate. Later whorls with relatively coarse ribs (12 per $\mathrm{mm}$ on penultimate whorl). Sutures relatively shallow. Umbilicus narrowly open. Peristome incomplete parietally. Outer palatal surface of aperture with a depression corresponding to the palatal tooth. Dentition 5-fold, consisting of: one lamella-like parietal tooth and one additional parietal denticle; one slab-like palatal tooth, forming a narrow parieto-palatal sinus; one basal denticle; and a deep-set, folded columellar baffle, but no shallower columellar denticles. Shells and anatomy of juveniles unknown. 


\section{Range and habitat}

Evergreen coastal thicket at the type locality.

\section{Remarks}

This taxon is in some respects intermediate between the type specimens of D. r. radius comb. nov. and D. b. browni comb. nov., and thus distinct from either, yet difficult to place. It is larger and not as squat as other D. browni comb. nov. s.l., and lacks the additional basal denticle and shallower columellar dentition. Conversely, it has a parietal denticle not seen in D. radius comb. nov. s.l, is smaller and squatter than most $D$. radius comb. nov. s.l., and has a longer and narrower parieto-palatal sinus than any D. radius comb. nov. s.l. Mafia Island, from which no other Dadagulella gen. nov. are yet known, lies at almost the same latitude $\left(7.8^{\circ} \mathrm{S}\right)$ as the apparent northernmost limit of $D$. b. browni comb. nov. in mainland Tanzania. Given the morphology of this specimen, its latitude and its isolation as an island population, we treat it as a subspecies of $D$. browni comb. nov.

\section{Dadagulella browni semulikiensis subsp. nov} Figs 22, 55, 84; Table 1

\section{Etymology}

From Semuliki.

\section{Type material examined}

UGANDA: holotype NMW.Z.1997.009.00004: 1 ad., Semuliki National Park $\left(00.82^{\circ} \mathrm{N}, 30.16^{\circ} \mathrm{E}\right)$, Bwamba County, Bundibugyo District, lowland Guineo-Congolian rainforest (site IIR), approx. $760 \mathrm{~m}$ alt., leg. PT \& J.A. Allen, 14 Jul. 1996. Paratype NMW.Z.1997.009.00005: 1 ad., data as holotype.

\section{Other material examined}

UGANDA: NMW.Z.1997.009.00006: 1 juv., data as holotype.

\section{Description}

Shell (Figs 22, 55). Small (3.20-3.30 mm high x $1.90 \mathrm{~mm}$ wide), of 6.0-6.5 whorls. Ovate-acuminate, spire broadly acuminate (spire angle around $67^{\circ}$ ). Apex pointed. Embryonic whorls smoothly granulate. Later whorls with relatively coarse ribs (around 12 per $\mathrm{mm}$ on penultimate whorl). Sutures relatively shallow. Umbilicus closed. Peristome complete. Outer palatal surface of aperture with a depression corresponding to the palatal tooth, and another much weaker one corresponding to the basal tooth. Dentition 8-fold, consisting of: one lamella-like parietal tooth and one additional parietal denticle; one slab-like palatal tooth, forming a long, narrow parieto-palatal sinus; two basal denticles; a deepset columellar baffle and two shallower columellar denticles. Juvenile shell with 3-fold dentition: one parietal lamella; one bifid basal tooth; and one baso-columellar tooth. Anatomy unknown.

\section{Range and habitat}

Lowland Guineo-Congolian forest at the type locality in the valley of the Albertine Rift.

\section{Remarks}

This subspecies is very similar to $D . b$. browni comb. nov. and, if found together, the two might not at first glance be distinguished. However, D. b. semulikiensis subsp. nov. is approximately $10 \%$ taller and wider, has shallower sutures and a more complete peristome. Its parieto-palatal sinus is longer and narrower than that of $D$. b. browni comb. nov., and does not widen appreciably towards its inner end. The type localities of $D$. b. browni comb. nov. and D. b. semulikiensis subsp. nov. are over $3000 \mathrm{~km}$ 
apart, in very different biogeographic and climatic regions. Although several snail species are known to range between South and East Africa, most are either species of the coastal strip, or are widely distributed throughout the entire area. Dadagulella gen. nov. has not been recorded from much of the intervening area of East Africa and is represented in the Albertine Rift otherwise only by D. selene (van Bruggen \& Van Goethem, 1999) comb. nov. It remains possible that the Semuliki population has descended from D. b. browni comb. nov., introduced by man from Tanzania or further to the south, and that the morphological differences are mainly ecophenotypic. However, in the light of these differences and the great geographic separation, we treat it as a subspecies of D. browni comb. nov. as we do with D. b. mafiensis subsp. nov.

Dadagulella delgada (Muratov, 2010) comb. nov.

Figs 27, 84; Table 1

Gulella delgada Muratov, 2010: 274, 276-277, figs 37, 39-45.

\section{Type material examined}

None.

\section{Type locality}

"Mozambique: Cabo Delgado: $1.1 \mathrm{~km}$ WNW of lighthouse, $19 \mathrm{~km}$ NE of Palma, $10.68883^{\circ} \mathrm{S}$, 40.62806 E, alt. $11 \mathrm{~m}, 24$ Nov. 2009, I.V. Muratov.” (Muratov 2010).

\section{Other material examined}

None.

\section{Description}

SHeLl (Fig. 27). Medium-sized (3.80-4.00 mm high x 1.80-1.80 mm wide), of 6.5-7.5 whorls. Elongate ovate-acuminate, spire narrowly acuminate (spire angle $43-49^{\circ}$ ). Apex sharply pointed (with axis slightly deviated in one syntype). Embryonic whorls smooth. Later whorls with very few, widely-spaced, flaring, subtriangular, lamella-like ribs (about 7 per $\mathrm{mm}$ on penultimate whorl). Sutures very deep. Umbilicus narrowly open. Peristome incomplete parietally. Outer palatal surface of aperture with a depression corresponding to the palatal tooth. Dentition 5-fold, consisting of: one lamella-like parietal tooth; one slab-like palatal tooth, forming a parieto-palatal sinus; one basal denticle; a deep-set columellar baffle and one shallower columellar denticle. Juvenile shells with 3-fold dentition: one parietal lamella; one basal tooth and one columellar thickening. Muratov (2010) found no internal dentition in the upper whorls. Anatomy unknown.

\section{Range and habitat}

At the type locality, vegetation on coral rag (Muratov 2010: 284).

\section{Remarks}

The few, flaring, lamella-like ribs and elongate, narrowly acuminate spire of $D$. delgada comb. nov. allow it to be separated from other species, including some D. radius comb. nov. s.l. which it resembles in size and dentition. 


\section{Dadagulella ecclesiola sp. nov. urn:Isid:zoobank.org:act:CCE56537-B647-4144-AB07-FE322A139087}

Figs 28, 49, 56, 84; Table 1

\section{Etymology}

From Latin 'ecclesiola', feminine, diminutive of 'church' (or 'the church'); used arbitrarily to distinguish the species from $D$. minareta sp. nov. with which it occurs.

\section{Type material examined}

TANZANIA: holotype NMW.Z.2003.001.00015: 1 ad., Kimboza Forest Reserve $\left(7.01^{\circ} \mathrm{S}, 37.78^{\circ} \mathrm{E}\right)$, Uluguru Mts, Morogoro District, lowland forest on limestone, approx. $300 \mathrm{~m}$ alt., leg. BR, PT, MBS, \& CFN, 5 Feb. 2003. Paratypes NMW.Z.2003.001.00016: 8 ads, data as holotype. Paratype MRAC. MT.803794: 1 ad., data as holotype. Paratype NHMUK.20120259: 1 ad., data as holotype. Paratype NMK: 1 ad., data as holotype. Paratype NMT: 1 ad., data as holotype. Paratype NMSA.L8692/T3061: 1 ad., data as holotype. Paratype RMNH.MOL.288089: 1 ad., data as holotype.

\section{Other material examined}

TANZANIA: NMW.Z.2003.001.00017: 1 ad., data as holotype, sequenced by Rowson et al. (2010a) as "Gulella cf. browni Uluguru". NMW.Z.2003.001.00018: 3 ads in poor condition, 3 juvs, data as holotype.

\section{Description}

SHELl (Figs 28, 49, 56). Small to medium-sized (3.20-3.70 mm high x 1.80-1.90 mm wide), of 5.5-7.0 whorls. Ovate-acuminate, spire narrowly accuminate (spire angle $53-65^{\circ}$ ). Apex pointed. Embryonic whorls smoothly granulate. Later whorls with relatively coarse, often sinuous ribs (8-14 per mm on penultimate whorl). Sutures deep. Umbilicus closed. Peristome complete. Outer palatal surface of aperture with a depression, often furrow-like, corresponding to the palatal tooth. Dentition 4-fold, consisting of: one strongly oblique parietal tooth, V-shaped when shell turned to the left; one large slablike palatal tooth, forming a narrow, horizontal parieto-palatal sinus; and a deep-set columellar baffle. A basal denticle is also present, presumably in all specimens, but is partly or completely hidden by the palatal tooth which occludes much of the aperture. The denticle is visible when the shell is turned to the right (Fig. 56). Juvenile shells not known with certainty: an individual from Kimboza (Fig. 49), with dentition like that of a juvenile D. r. radius comb. nov., might belong to this species. Anatomy unknown.

\section{Range and habitat}

In forest at the type locality in the eastern Tanzanian lowlands.

\section{Remarks}

This species has much simpler dentition than D. minareta sp. nov. (which also occurs at Kimboza), and is usually smaller, with straight rather than sinuous ribs. Its dentition is more like that of D. r. radius comb. nov. (which again also occurs at Kimboza; Fig. 16) and D. minuscula minuscula (Morelet, 1877) comb. nov. but $D$. ecclesiola sp. nov. lacks the shallow columellar tooth, has a hidden or partly hidden basal denticle, and has a much narrower parieto-palatal sinus. It further differs from D. minuscula minuscula comb. nov. in having stronger ribs. 


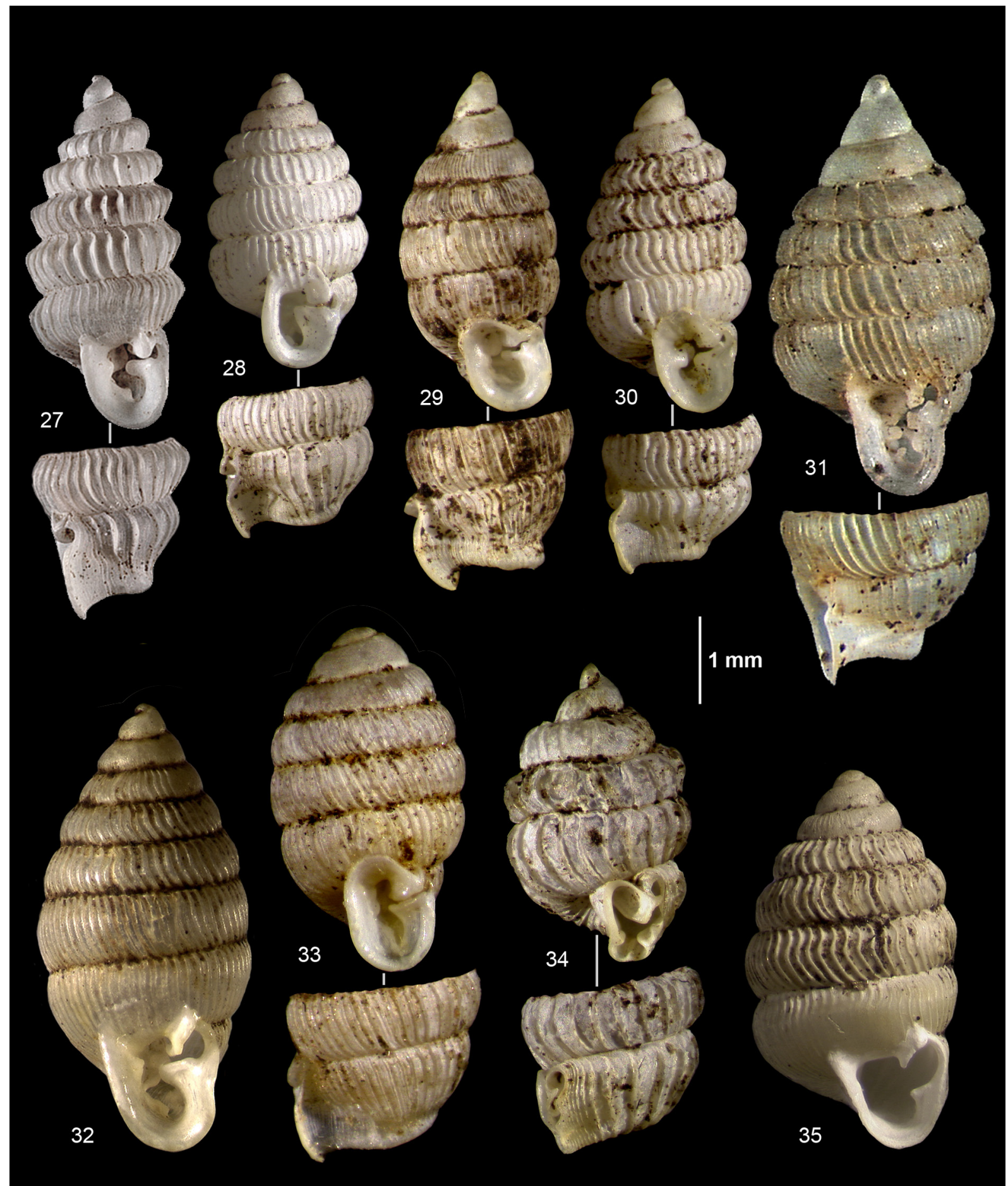

Figs 27-35. Adult shells of Dadagulella gen. nov. species. 27. D. delgada (Muratov, 2010) comb. nov., syntype, Cabo Delgado (after Muratov 2010). 28. D. ecclesiola sp. nov., holotype, Kimboza. 29. D. cresswelli sp. nov., holotype, Ngorongoro. 30. D. minareta sp. nov., holotype, Kimboza. 31. D. cuspidata (Verdcourt, 1962) comb. nov., holotype, Shume. 32. D. pembensis sp. nov., holotype, Ngezi. 33. D. nictitans (Rowson \& Lange, 2007) comb. nov., holotype, Macha. 34. D. frontierarum sp. nov., holotype, Mtai. 35. D. delta sp. nov., holotype, Mwanihana. 


\section{Dadagulella cresswelli sp. nov. urn:1sid:zoobank.org:act:B3362D6F-2118-4D1D-8B25-098E25B0C3B2}

Figs 29, 57, 84; Table 1

\section{Etymology}

After Pete Cresswell, who collected the specimen.

\section{Type material examined}

TANZANIA: holotype NMW.Z.2012.042.00001: 1 ad., Ngorongoro Crater, Arusha Region, crater rim on southeastern side, heavy rainforest leaf litter, leg. P.L. Cresswell, 2 Jun.1996.

\section{Other material examined}

None.

\section{Description}

SHELl (Figs 29, 57). Medium-sized (3.70 mm high x $1.80 \mathrm{~mm}$ wide), of 7.0 whorls. Ovate-acuminate, spire coeloconoid (spire angle $52^{\circ}$ ). Apex sharply pointed. Embryonic whorls smoothly granulate. Later whorls with relatively fine ribs (13 per mm on penultimate whorl). Sutures shallow. Umbilicus narrowly open. Peristome complete. Outer palatal surface of aperture with a very deep, long, furrow-like depression corresponding to the palatal tooth. Dentition 5-fold, consisting of: one V-shaped parietal tooth; one bifid slab-like palatal tooth, forming a clear parieto-palatal sinus, with the upper cusp projecting into the sinus; a deep-set columellar baffle and two shallower columellar denticles. Shells and anatomy of juveniles unknown.

\section{Range and habitat}

Forest at the type locality in northern Tanzania. The vegetation is presumably of a montane type, since the crater floor is above $1700 \mathrm{~m}$ while the rim rises to over $2400 \mathrm{~m}$ or higher.

\section{Remarks}

This species is distinctive in its deep, long furrow on the outer palatal surface in combination with the coeloconoid spire and dentition. D. minerata sp. nov. shares these features, but differs in having weaker ribs and less complex dentition. It is the only Dadagulella gen. nov. species thus far collected in the volcanic (as opposed to block-faulted) highlands of Tanzania or Kenya.

\section{Dadagulella minareta sp. nov. urn:Isid:zoobank.org:act:6AF1E4AF-D1D2-4C5A-9FCA-AC5B15A07204}

Figs 30, 50, 58, 84; Table 1

\section{Etymology}

From English 'minaret', the tower of a mosque; Latinized by the addition of the feminine ending ' $-a$ '; used as a noun in apposition.

\section{Type material examined}

TANZANIA: holotype NMW.Z.2003.001.00010: 1 ad., Kimboza Forest Reserve $\left(7.01^{\circ} \mathrm{S}, 37.78^{\circ} \mathrm{E}\right)$, Uluguru Mts, Morogoro District, lowland forest on limestone, approx. $300 \mathrm{~m}$ alt., leg. BR, PT, MBS \& CFN, 5 Feb. 2003. Paratype NMW.Z.2003.001.00011: 1 ad., data as holotype. Paratypes NMW.Z.2003.001.00012: 3 ads, data as holotype. Paratype NMW.Z.2003.001.00013: 1 ad., data as holotype. Paratype MRAC.MT.803795: 1 ad., data as holotype. Paratype NHMUK.20120260: 1 ad., 
data as holotype. Paratype NMK: 1 ad., data as holotype. Paratypes NMT: 2 ads, data as holotype. Paratype NMSA.L863/T3062: 1 ad., data as holotype. Paratype RMNH.288088: 1 ad., data as holotype.

\section{Other material examined}

TANZANIA: NMW.Z.2003.001.00014: 1 juv., data as holotype. NMW.Z.2004.016.00008: 2 ads, Kanga Forest Reserve $\left(6.01^{\circ} \mathrm{S}, 37.72^{\circ} \mathrm{E}\right)$, Nguru Mts, Mvomero District, lowland forest at approx. $450 \mathrm{~m}$ alt., leg. BR, PT \& CFN, 26 Jun. 2004. NMW.Z.1995.016.00012: 4 ads, 1 juv. Pugu Forest $\left(6.89^{\circ} \mathrm{S}, 39.09^{\circ} \mathrm{E}\right)$, S of Dar es Salaam (site I), leg. PT, 6 Mar. 1995. The juv. in the Pugu lot may not be conspecific.

\section{Description}

Shell (Figs 30, 50, 58). Medium-sized (3.40-4.00 mm high x 1.80-2.00 mm wide), of 6.0-7.0 whorls. Ovate-acuminate, spire acuminate to coeloconoid (spire angle 48-63). Apex sharply pointed. Embryonic whorls with fine regular radial striae; smoothly granulate where worn. Later whorls with relatively coarse, usually sinuous ribs (10-13 per mm on penultimate whorl). Sutures deep. Umbilicus narrowly open. Peristome complete or incomplete parietally. Outer palatal surface of aperture with a furrow-like depression corresponding to the palatal tooth. Dentition 5-fold to 7-fold, consisting of: one V-shaped parietal tooth; one bifid, slab-like, deeply in-running palatal tooth, not usually forming a parieto-palatal sinus; and two columellar teeth. The upper of these is large and characteristically squarish, running in to form a columellar baffle which is connected to it; the lower columellar tooth is a small in-running denticle. Additional teeth include an extra parietal tooth and/or one or two shallow columellar denticles. Juvenile shell (Fig. 50) with 3-fold to 4-fold dentition: one very short parietal lamella; two basal teeth (or one bifid tooth); and one columellar tooth. Earlier basal and columellar teeth are retained.

Cephalopodium. Pale yellow, with apricot tentacle retractors.

SALIVARY GLANDS. United, soft, not tumid, elongate, Y-shaped; each duct leaving at the apex of the lobe and evenly thick throughout.

RADULA. Not successfully prepared.

Genitalia. Vas deferens thickened prior to insertion on penis but apparently without diverticulum. Penial sheath absent but with a thin sheath-like layer contiguous with wall of lower penis. Interior of penis with weak radial pilasters and small rhombic pads. Apical part of penis with a broad "scoop" with microscopically serrated tip, but without large hook. Elsewhere in penis a single longitudinal row of short, simple hooks mounted on rhombic pads.

\section{Range and habitat}

In forest at the type locality and in Pugu Hills Nature Reserve, both in the eastern Tanzanian lowlands, and in lowland forest on Mt. Kanga in the Nguru Mts.

\section{Remarks}

The dentition, most noticeably the squared-off shallow columellar tooth that runs in to connect with the baffle, readily distinguishes this species from D. ecclesiola sp. nov. (which also occurs at Kimboza) and D. r. radius comb. nov. (which also occurs at both Kimboza and Pugu). It also distinguishes it from $D$. cuspidata (Verdcourt, 1962) comb. nov., with which it shares the strong upper columellar tooth and fine regular radial striae on the embryonic whorls. It differs from $D$. cresswelli sp. nov., with which it shares the furrow-like depression on the outer palatal surface, in dentition and in having stronger ribs. 
Dadagulella cuspidata (Verdcourt, 1962) comb. nov.

Figs 31, 59, 84; Table 1

Gulella cuspidata Verdcourt, 1962: 3, 27-28, pl. 3, fig. 2.

“Gulella sp. nov." - Verdcourt 1958: 94, 100, fig. 10.

Gulella cuspidata - van Bruggen 1969: 71. — Verdcourt 1983: 232. — Richardson 1988: 72. — Verdcourt 1996: 136. — Tattersfield 1998b: 37. — Tattersfield et al. 1998: 135. — van Bruggen 2000: 233. — Verdcourt 2006: 46. — Rowson \& Lange 2007: 31. — Muratov 2010: 277.

\section{Type material examined}

TANZANIA: holotype MRAC.792352: 1 ad., Worlds View, Shume, West Usambara Mts $\left(4.70^{\circ} \mathrm{S}\right.$, $38.20^{\circ} \mathrm{E}$ ), in rather dry evergreen forest, leg. B. \& L. Verdcourt, Dec. 1956.

\section{Other material examined}

None.

\section{Description}

SHell (Figs 31, 59). Large (4.30-4.80 mm high x $1.80 \times 2.50 \mathrm{~mm}$ wide), of 7.75 whorls. Ovate-acuminate, spire coeloconoid (spire angle $58^{\circ}$ ). Apex sharply pointed. Embryonic whorls appear smooth but with fine regular radial striae. Later whorls with relatively few, coarse ribs (about 8 per $\mathrm{mm}$ on penultimate whorl). Sutures of intermediate depth. Umbilicus narrowly open. Peristome incomplete parietally. Outer palatal surface of aperture with a furrow-like depression corresponding to the upper palatal tooth. Dentition 6-fold (alternatively recognisable as 5-fold), consisting of: one lamella-like parietal tooth; two palatal teeth, the upper much larger and forming a parieto-palatal sinus; one basal, in-running tooth; and a strong, squarish columellar tooth, running in to form a columellar baffle which is connected to it. Juvenile shells and anatomy unknown.

\section{Range and habitat}

Elevation not stated but probably between $1500-2000 \mathrm{~m}$ at the type locality in northeastern Tanzania.

\section{Remarks}

This species differs from $D$. minareta sp. nov. in having two palatal teeth, in having a basal tooth, in the shape of the parietal tooth, and in size.

\section{Dadagulella pembensis sp. nov. urn:Isid:zoobank.org:act:4442210F-A097-400D-B34F-96A4B7677CE7}

Figs $32,46,60,66-68,70,75,79-80,84$; Table 1

““Gulella” radius (Preston, 1910)" - Rowson et al. 2010b: 9-10, 28-29, figs 60-61.

\section{Etymology}

From Pemba Island, with the final 'a' elided for euphony.

\section{Type material examined}

TANZANIA: holotype NMW.Z.2009.013.00227: 1 ad., Ngezi Forest Reserve $\left(4.94^{\circ} \mathrm{S}, 39.69^{\circ} \mathrm{E}\right)$, Pemba I., Zanzibar, dry forest on dark, sandy soil on coral rag on Tondooni peninsula within reserve, leg. BR, B. H. Warren \& CFN, 7 Feb. 2009; fig. 60 in Rowson et al. (2010b). Paratypes NMW.Z.2009.013.00228: 2 ads, data as holotype. Paratypes MRAC.MT.803796-7: 2 ads, data as holotype. Paratypes NHMUK.20120261: 
2 ads, data as holotype. Paratypes NMK: 2 ads, data as holotype. Paratypes NMT: 2 ads, data as holotype. Paratypes NMSA.L8694/T3063: 2 ads, data as holotype. Paratypes RMNH.MOL.288090: 2 ads, data as holotype.

\section{Other material examined}

TANZANIA: NMW.Z.2009.013.00229: 15 juvs, data as holotype; one figured as fig. 61 in Rowson

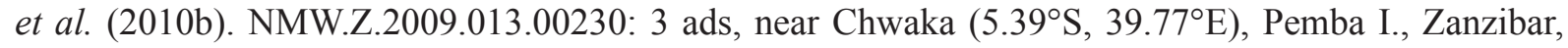
clove and fruit tree woodland on dark, sandy soil, leg. BR, B.H. Warren \& CFN, 15 Feb. 2009. NMW.Z.2009.013.00231: 3 ads, Msitu Mkuu Forest Reserve $\left(5.00^{\circ} \mathrm{S}, 39.83^{\circ} \mathrm{E}\right)$, Pemba I., Zanzibar, moist forest on dark (not sandy) soil on coral rag in high forest in north of reserve, leg. BR, B.H. Warren \& CFN, 10 Feb. 2009. NMW.Z.2009.013.00232: 3 ads, Ngezi Forest Reserve, Pemba I., Zanzibar, dry forest and thicket on dark, sandy soil on coral rag on coast of Tondooni peninsula within reserve, leg. BR, B.H. Warren \& CFN, 8 Feb. 2009. NMW.Z.2009.013: Many additional ads and juvs from the type locality and other sites on Pemba I., Feb. 2009; see table 2 of Rowson et al. (2010b).

\section{Description}

Shell (Figs 32, 46, 60). Large (4.80-5.50 mm high x 2.00-2.50 mm wide), of 6.5-7.5 whorls. Ovateacuminate, spire narrowly to broadly acuminate (spire angle $51-65^{\circ}$ ). Apex sharply pointed. Embryonic whorls smoothly granulate. Later whorls with relatively coarse ribs (12-15 per mm on penultimate whorl). Sutures shallow, shell appearing relatively straight-sided. Umbilicus closed or nearly so. Peristome complete, or incomplete parietally. Outer palatal surface of aperture with a depression corresponding to the palatal tooth and often another corresponding to the basal tooth. Dentition 6-fold, consisting of: one lamella-like parietal tooth; one slab-like palatal tooth, forming a parieto-palatal sinus; one basal denticle; a deep-set columellar baffle, sometimes folded, sub-bifid or sub-trifid; and two shallower, broad columellar denticles. Juvenile shells (Fig. 46) with 3-fold dentition, similar to some forms of $D$. r. radius comb. nov.: one parietal lamella; one basal tooth; and one columellar thickening. Earlier basal teeth are retained in juveniles.

Cephalopodium. Pale yellow, with apricot to orange tentacle retractors.

SaLivary GLANDS (Fig. 70). United, soft, not tumid, elongate, Y-shaped; each duct leaving at the apex of the lobe and evenly thick throughout.

RADULA (Figs 66-68). With a unicuspid central tooth and around 15 laterals in each half-row, gradually diminishing in size laterally. All laterals bicuspid, tricuspid, or quadricuspid, with outer cusps much smaller than inner cusps. Teeth delicate, short and flake-like at the ventral end of the radular ribbon.

Genitalia (Figs 75, 79, 80). Vas deferens appearing thickened prior to insertion on penis, but actually with a short, broad parallel diverticulum. Penial sheath absent but with a thin sheath-like layer contiguous with wall of lower penis. Interior of penis with weak radial pilasters and small rhombic pads. Apical, muscular part of penis with a single large hook, associated with a spatulate "scoop" with microscopically serrated tip. Elsewhere in penis, one or two longitudinal rows of short, simple hooks mounted on rhombic pads. "Spermatophore" (see Discussion) present in penis of two Ngezi specimens; partially digested remains in bursa of another.

\section{Range and habitat}

Pemba Island, Tanzania, where widespread in forest and other vegetated habitats. 


\section{Remarks}

This species was discussed by Rowson et al. (2010b), who suggested a thorough revision of the group to establish whether the Pemba populations were part of a variable $D$. radius comb. nov. or a subspecies or species endemic to Pemba. This uncertainty was incorporated into their conclusions on endemism on the island (Rowson et al. 2010b: 28-29, 32). We find here that there is little or no overlap with $D$. radius comb. nov. s.l. or other species, so conclude that this is an island endemic, which we here name $D$. pembensis sp. nov. Like specimens of D. r. radius comb. nov. on the opposite mainland at Amboni (e.g. Figs 15,53), D. pembensis sp. nov. is large and has a complex pattern of 6-fold dentition. However it is distinguishable from them by its even larger size, shallower sutures, and having on average an extra 0.5 whorls. It differs from $D$. minuscula mahorana subsp. nov. which has similar dentition, in its larger size, shallower sutures, and stronger and more widely spaced ribs.

Dadagulella nictitans (Rowson \& Lange, 2007) comb. nov. Figs 33, 84; Table 1

Gulella nictitans Rowson \& Lange, 2007: 27-31, figs 4-7, 14-19.

\section{Type material examined}

KENYA: holotype NMK: 1 ad., Taita Hills, Macha Forest Reserve $\left(3.45^{\circ} \mathrm{S}, 38.37^{\circ} \mathrm{E}\right)$, leaf litter in indigenous forest (site IB), 1550 m alt., leg. C.N. Lange, 27 Nov. 1998. Paratypes NMW.Z.2007.024.00007-00009: 3 ads, data as holotype. Paratype NMW.Z.2007.024.00010: 1 juv., data as holotype.

\section{Other material examined}

None.

\section{Description}

Shell (Fig. 33). Medium-sized (3.60-3.90 mm high x 2.00-2.20 mm wide), of 5.5 whorls. Ovateacuminate, although spire (spire angle $64-69^{\circ}$ ) less acuminate than in other Dadagulella gen. nov. Apex rounded. Embryonic whorls smoothly granulate. Later whorls with relatively coarse ribs (13-15 per $\mathrm{mm}$ on penultimate whorl). Sutures of intermediate depth. Umbilicus closed or nearly so. Peristome complete. Outer palatal surface of aperture with a long, furrow-like depression corresponding to the palatal tooth. Dentition 5-fold or 6-fold, consisting of: one V-shaped parietal tooth; one slab-like palatal tooth, forming a conspicuous and narrow parieto-palatal sinus; and two to three shallow columellar teeth, the lower the largest. A deep set-columellar baffle is partly or completely hidden by the constricted aperture, while a basal denticle is completely hidden behind the palatal tooth. However, the baffle and basal denticle are probably present in all specimens. One broken juvenile shell is known; it appears to lack teeth.

Cephalopodium. Pale cream, with pale tentacle retractors.

SaLIVARY GLANDS. United, soft, not tumid, elongate, Y-shaped; each duct leaving at the apex of the lobe and evenly thick throughout.

RADULA. Not successfully prepared.

Genitalia. Figured in Rowson \& Lange (2007).Vas deferens thickened prior to insertion on penis but apparently without diverticulum. Penial sheath absent. Interior of penis with weak radial pilasters, a single longitudinal pilaster, and small rhombic pads. Apical, muscular part of penis with two large hooks, associated with a spatulate "scoop" with microscopically serrated tip. Elsewhere in penis a single longitudinal row of short, simple hooks mounted on rhombic pads. 


\section{Range and habitat}

Montane forest (1400-1900 m) at the type locality and three other Forest Reserves in the Taita Hills, southeastern Kenya (Rowson \& Lange 2007).

\section{Remarks}

This species is included in Dadagulella gen. nov. on the basis of the apical penial scoop and hooks, and the Y-shaped salivary gland. Its shell features are consistent with inclusion in Dadagulella gen. nov. although the apex is more rounded than in other species. A slightly or strongly rounded apex occurs in $D$. selene comb. nov. and D. meredithae comb. nov. The parieto-palatal sinus, hidden basal denticle, and columellar dentition of $D$. nictitans comb. nov. allow it to be separated from other species.

Dadagulella frontierarum sp. nov. urn:Isid:zoobank.org:act:9D028B17-9FCB-47E8-96B1-5901B8E3EA4E

Figs 34, 61, 84; Table 1

\section{Etymology}

After Frontier Tanzania, the organisation which collected the specimens; given the ending '-arum' for a feminine noun in the genitive plural.

\section{Type material examined}

TANZANIA: holotype NMW.Z.2003.074.00001: 1 ad., Mtai Forest Reserve $\left(4.87^{\circ} \mathrm{S}, 38.77^{\circ} \mathrm{E}\right)$, East Usambara Mts, Muheza District (plot 69/3), submontane forest at $970 \mathrm{~m}$ alt., leg. Frontier Tanzania, 8 Mar. 1997. Paratypes NMW.Z.2003.074.00002: 2 ads, data as holotype. Paratype NMW.Z.2003.074.00003: 1 ad., data as holotype. Paratype NMW.Z.2003.074.00004: 1 ad., data as holotype but 7 Mar. 1997. Paratypes NMT: 2 ads, data as holotype.

\section{Other material examined}

None.

\section{Description}

Shell (Figs 34, 61). Medium-sized (3.15-3.40 mm high x 1.80-2.05 mm wide), of 4.5-5.0 whorls. Ovateacuminate, spire narrowly acuminate (spire angle $68-77^{\circ}$ ). Apex sharply pointed. Embryonic whorls smoothly granulate. Later whorls with few, widely-spaced, coarse ribs (5-7 per mm on penultimate whorl). Sutures very deep. Umbilicus narrowly open. Peristome complete, almost detached. Outer palatal surface of aperture with a depression corresponding to the lower palatal teeth. Dentition 6-fold, consisting of: one complex, V-shaped and flaring parietal tooth; three palatal teeth, the lower two larger and set low down on the palatal surface, not forming a parieto-palatal sinus; one basal, in-running denticle; and one shallow but strong, in-running columellar tooth. Shells and anatomy of juveniles unknown.

\section{Range and habitat}

Submontane forest (970 m elevation) in the East Usambara Mountains, northeastern Tanzania.

\section{Remarks}

The complex dentition and detached peristome of $D$. frontierarum sp. nov. are unlike that of any other Dadagulella gen. nov. species. It is also characteristic for its few whorls, few ribs and sharply pointed apex. Biogeographically a close relationship with other species in and around the East Usambaras would seem likely but there is no strong resemblance. 
Dadagulella delta sp. nov. urn:Isid:zoobank.org:act:BF3B1698-C8EF-4B28-89A8-D1AA85773A42

Figs 35, 72, 76, 81, 84; Table 1

“Gulella sp. 12" - Tattersfield et al. 2006: 52-53.

\section{Etymology}

From Greek 'delta', after the letter we originally used as an informal morphospecies name for the species; used as a noun in apposition.

\section{Type material examined}

TANZANIA: holotype NMW.Z.2003.001.00019: 1 ad., Mt. Mwanihana Forest Reserve (7.82 $\left.{ }^{\circ} \mathrm{S}, 36.83^{\circ} \mathrm{E}\right)$, Udzungwa Mts National Park, Kilombero District, forest at $1050 \mathrm{~m}$ alt., leg. BR, PT, MBS \& CFN, 29 Jan. 2003. Paratype NMW.Z.2003.001.00020: 1 ad., data as holotype but $1200 \mathrm{~m}$ alt., 30 Jan. 2003.

\section{Other material examined}

None.

\section{Description}

SHELL (Fig 32). Large (4.20-4.30 mm high x 2.10-2.40 mm wide), of 6.5 whorls. Ovate-acuminate, spire broadly acuminate (spire angle 56-66 ${ }^{\circ}$. Apex pointed. Embryonic whorls smoothly granulate. Later whorls with coarse, sinuous ribs (12-13 per mm on penultimate whorl). Sutures of intermediate depth. Umbilicus narrowly open. Peristome incomplete parietally. Outer palatal surface of aperture with a depression corresponding to the palatal tooth. Dentition weak, 3-fold (although could be interpreted as 2-fold or 4-fold), consisting of: one lamella-like parietal tooth; one weak palatal tooth, not forming a parieto-palatal sinus; a columellar baffle so deeply set as to be almost invisible in apertural view; and a very weak shallow columellar swelling. Juvenile shells unknown.

Cephalopodium. Pale cream, with pale tentacle retractors.

SALIVARY GLANDS (Fig. 72). United, soft, not tumid, elongate, bilobed; each duct leaving at the whitened apex of the lobe and evenly thick throughout.

RADULA. Not successfully prepared.

Genitalia (Figs 76, 81). Vas deferens appearing thickened prior to insertion on penis but actually with an elongate, parallel diverticulum. Penial sheath absent. Interior of penis with weak radial pilasters and small rhombic pads. Apical part of penis with a single large hook, associated with a spatulate "scoop" with microscopically serrated tip. Elsewhere in penis, an elongate cluster of short, simple hooks mounted on rhombic pads.

\section{Range and habitat}

Montane forest (1000-1200 m) in the Udzungwa Mountains, central Tanzania.

\section{Remarks}

This species is distinctive in its simple and weak dentition, weaker than in any other Dadagulella gen. nov. species except in D. rondoensis (Verdcourt, 1994) comb. nov. and D. conoidea (Verdcourt, 1996) comb. nov. which have a more conical shape. It can be distinguished from Gulella udzungwensis 
van Bruggen, 2003, which also occurs on Mt. Mwanihana (van Bruggen 2003), by having a more acuminate spire and more pointed apex, deeper sutures, sinuous ribs and no basal tooth.

Dadagulella selene (van Bruggen \& Van Goethem, 1999) comb. nov.

Figs 36, 84; Table 1

Gulella selene van Bruggen \& Van Goethem, 1999: 39-40, figs 11-12.

Gulella selene - van Bruggen 2000: 233.

\section{Type material examined}

DEMOCRATIC REPUBLIC OF CONGO: paratype RBINS.MT.1645: 1 ad., Kivu Province, Virunga National Park, northern sector, Kalivina River, tributary of the Talya Nord River, bamboo forest, Hagenia Moench, 1000-2720 m (approx. $0.0^{\circ} \mathrm{S}, 29.5^{\circ} \mathrm{E}$ ), leg. P. Vanschuytbroeck \& H. Synave, 28 Aug. 1953 (examined digital photograph only).

\section{Type locality}

"D.R.Congo, Kivu Province, Virunga National Park, northern sector, at Musabaki (=Musavaki) River, 2720 m" (van Bruggen \& Van Goethem 1999) (approx. 0.0, 29.5²).

\section{Other material examined}

None.

\section{Description}

SHell (Fig. 36). Medium-sized (3.60-3.70 mm high x 2.10-2.20 mm wide), of 6.0-6.25 whorls. Ovateacuminate, although spire (spire angle $70^{\circ}$ ) less acuminate than in other Dadagulella gen. nov. Apex rounded. Embryonic whorls "completely smooth, although there is a hint of spiral engraving" (van

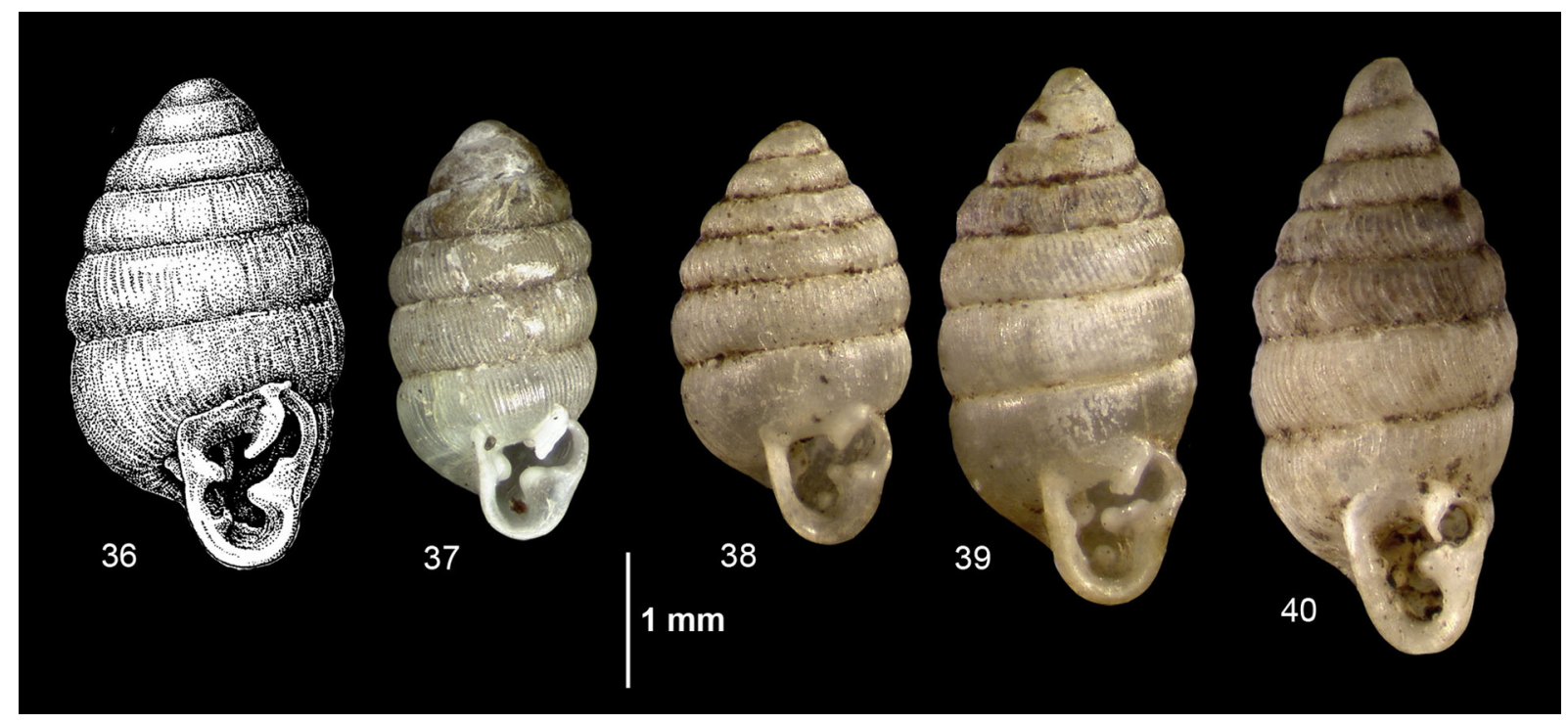

Figs 36-40. Adult shells of Dadagulella gen. nov. species. 36. D. selene (van Bruggen \& Van Goethem, 1999) comb. nov., holotype, Virunga NP (after van Bruggen \& Van Goethem 1999). 37. D. meredithae (van Bruggen, 2000), holotype, Nyika NP. 38. D. minuscula minuscula (Morelet, 1877), lectotype, Nzwani. 39. D. minuscula minuscula, paralectotype, Nzwani. 40. D. minuscula mahorana subsp. nov., holotype, Mayotte. 
Bruggen \& Van Goethem 1999). Later whorls with numerous, fine, very weak ribs (about 16 per mm on penultimate whorl). Sutures of intermediate depth. Umbilicus closed or nearly so. Peristome complete. Outer palatal surface of aperture with a depression corresponding to the palatal tooth. Dentition 5-fold, consisting of: one lamella-like parietal tooth; one bifid slab-like palatal tooth, not forming a parietopalatal sinus; a baso-columellar tooth or denticle; a deep-set columellar baffle and a shallower columellar tooth. Dentition alternatively recognisable as 6-fold, if the bifid palatal tooth is interpreted as two teeth (van Bruggen 1969). Juvenile shells and anatomy unknown.

\section{Range and habitat}

Montane forest (1000-2720 m) in the Albertine Rift. The type locality and the other in the Virunga National Park are in bamboo forest (van Bruggen \& Van Goethem 1999). Wronski \& Hausdorf (2010) also record it from montane forest at around $2300 \mathrm{~m}$ in Echuya Forest Reserve, southwestern Uganda.

\section{Remarks}

Van Bruggen \& Van Goethem (1999) considered this species to belong to the group of species among which van Bruggen (1969) placed D. browni comb. nov. They noted that within this group D. selene comb. nov. was the most weakly sculptured and had distinctive dentition. These comments are still applicable among the larger number of species we attribute to Dadagulella gen. nov. However, like D. browni semulikiensis subsp. nov., D. selene comb. nov. is notable for occurring far to the northwest of other Dadagulella gen. nov species. It deserves further study from the perspective of Conogulella Pilsbry, 1919 (see Discussion).

Dadagulella meredithae (van Bruggen, 2000) comb. nov. Figs 37, 84; Table 1

Gulella meredithae van Bruggen, 2000: 226-232, figs 1-7.

“... an as yet unidentified species from Malawi" - van Bruggen \& Meredith 1984: 165.

Gulella meredithae - Rowson \& Lange 2007: 31.

\section{Type material examined}

MALAWI: holotype RMNH.59399: 1 ad., Nyika National Park (approx. 10.6 $\mathrm{S}, 33.8^{\circ} \mathrm{E}$ ), Rumphi District, Juniper Forest, approx. 2100 m alt., leg. H.M. Meredith, 16 Sep. 1983.

\section{Other material examined}

None.

\section{Description}

SHELl (Fig. 37). Small (2.30-3.10 mm high x 1.40-1.60 mm wide), of 5.5-“<6" whorls. Ovate-acuminate, although spire (spire angle $58-77^{\circ}$ ) less acuminate than in other Dadagulella gen. nov species. Apex rounded (in holotype) to weakly pointed. Embryonic whorls smoothly granulate. Later whorls with very fine, very numerous ribs (about 27 per $\mathrm{mm}$ on penultimate whorl). Sutures of intermediate depth. Umbilicus closed or nearly so. Peristome incomplete parietally. Outer palatal surface of aperture with a depression corresponding to the palatal tooth. Dentition 3-fold to 4-fold, consisting of at least: one lamella-like parietal tooth; one slab-like palatal tooth, not forming a parieto-palatal sinus; and a mammillate columellar baffle. Additional teeth limited to a shallow, weak columellar swelling. Juvenile shells with 2-fold to 3-fold dentition: one parietal tooth; one columellar tooth; and usually one basal tooth (termed labral by van Bruggen 2000). Van Bruggen (2000) showed that earlier sets of dentition are 
visible through the shells of some transparent juveniles, even in the preceding whorls, suggesting slow or no resorbtion. Anatomy unknown.

\section{Range and habitat}

Montane forest (above $1500 \mathrm{~m}$ to around $2450 \mathrm{~m}$ ) in northern and central Malawi, and adjacent part of Zambia (Chowo Forest). Van Bruggen (2000) suspected it to range into parts of Tanzania adjoining northern Malawi.

\section{Remarks}

This species is distinctive in its small size, very fine, numerous ribs, and dentition. It differs from $D$. radius comb. nov. s.l. and D. browni comb. nov. s.l. in the lack of a basal tooth or denticle. The apex is rounded in the holotype but more conical in paratypes figured by van Bruggen (2000).

Dadagulella minuscula minuscula (Morelet, 1877) comb. nov. Figs 38-39, 62-63, 84; Table 1

Pupa minuscula Morelet, 1877: 340.

Pupa fischeriana Morelet, 1877: pl. XII, fig. 5 (objective synonym).

Ennea fischeriana - Morelet 1881: 230-231. — Richardson 1988: 103 (objective synonym). Ennea (Gulella) fischeriana - Tryon 1885: 100, pl. 20, fig. 39.

Ennea (Uniplicaria) fischeriana - Kobelt 1905: 166, pl. 22, fig. 10; 1910: 158.

Pupa minuscula - Kobelt 1905: 166; 1910: 158. — van Bruggen 1975: 166.

Ennea minuscula - Preston 1910: 529.

Gulella minuscula Morelet (non Gulella minuscula Emberton \& Pearce, 2000) - Fischer-Piette \& Vukadinovic 1974: 55. — Richardson 1988: 103. — Rowson 2007a: 441-442. — Rowson \& Lange 2007: 31. - Muratov 2010: 277.

\section{Type material examined}

COMOROS: lectotype (here designated) and paralectotype NHMUK.1893.2.4.87-88: 2 ads, "Anjouan I." (Nzwani I., approx. $12.22^{\circ} \mathrm{S}, 44.45^{\circ} \mathrm{E}$ ), labelled "types". The smaller of the two specimens is apparently the shell figured in Morelet (1877: pl. XII, fig. 5) under the name " fischeriana". It was evidently formerly on a white card mount. This shell is here designated lectotype, while the larger is considered a paralectotype (although Morelet's description could in fact have been made from a single shell).

\section{Type locality}

"Dans l'île d'Anjouan (Johanna)" (Morelet 1877; from title of paper).

\section{Description}

Shell (Figs 38-39, 62-63). Variable in size, shape and dentition, small to large (3.00-4.10 mm high x 1.90-2.00 mm wide), of 6.5-7.0 whorls. Ovate-acuminate, spire broadly acuminate (spire angle $48-63^{\circ}$ ). Apex pointed. Embryonic whorls smoothly granulate. Later whorls with relatively fine, numerous ribs (10-13 per mm on penultimate whorl). Sutures relatively deep. Umbilicus closed or nearly so. Peristome complete, or incomplete parietally. Outer palatal surface of aperture with a depression corresponding to the palatal tooth. Dentition 4-fold (lectotype, Figs 38, 62) to 5-fold (paralectotype, Figs 39, 63), consisting of: one lamella-like parietal tooth; one slab-like palatal tooth, often bifid, but with parietopalatal sinus barely present; one basal denticle; and one deep-set columellar baffle, always visible. An additional shallow columellar denticle is present in the paralectotype. Shells and anatomy of juveniles unknown. 


\section{Range and habitat}

Nzwani (Anjouan) island in the Comoros archipelago; habitat unknown.

\section{Remarks}

Morelet (1877) described this species from Anjouan (type locality implied by the paper's title) under the name "Pupa minuscula" but figured it under the name "Pupa fischeriana" (pl. XII, fig. 5). In the paper he compared it to three species from "Île Bourbon" (Réunion), but none is very like it, suggesting Morelet was unaware of other Dadagulella gen. nov. species and probably meaning that D. m. minuscula comb. nov. was the first species of the group to be collected. Two of the Réunion species are streptaxids of the Mascarene genus Gonospira Swainson, 1840 while the third belongs to the Pupillidae Turton, 1831 (see Griffiths \& Florens 2006). Although Kobelt $(1905,1910)$ classified D. m. minuscula comb. nov. (under fischeriana) in the subgenus Ennea (Uniplicaria) L. Pfeiffer, 1856, it is very unlike Pupa cerea Dunker, 1848, the type species of Uniplicaria. Preston (1910) made a more relevant comparison in his description of Ennea radius, noting that his species had coarser ribs, a columellar denticle, and a bifid palatal tooth that were absent in D. m. minuscula comb. nov. Given these remarks and the fact that Preston cited only Anjouan as a locality for D. m. minuscula comb. nov., it thus appears he examined only the lectotype of the latter or material that was very like it. We agree that these features distinguish the lectotype of $D$. m. minuscula comb. nov. from that of D. r. radius comb. nov. However, the paralectotype (if it is such; see also below) of D. m. minuscula comb. nov., while having similarly fine ribs, has a stronger shallow columellar denticle that resembles that of D. r. radius comb. nov. Although we have seen no mainland specimen that exactly matches either of them, both specimens of $D$. m. minuscula comb. nov. fall within the range of variation seen in D. r. radius comb. nov. in other respects. It is therefore possible that the two taxa are synonymous, in which case Morelet's name would take priority over Preston's. It is even possible that D. minuscula comb. nov. s.l. consists of populations of D. radius comb. nov. s.l. derived from specimens introduced from the African mainland (the alternative, that $D$. radius comb. nov. s.l. was introduced into East Africa from the Comoros appears unlikely given the variation seen in East African populations and the many similar species there). That said, the isolated, volcanic Comoros archipelago comprises a region of endemism in itself and D. minuscula comb. nov. s.l. could easily be a Comoros endemic whose overlapping variation with D. radius comb. nov. s.l. is due to homoplasy. Resolving the relationships between these two taxa, and D. m. mahorana subsp. nov. below, is likely to require anatomical or molecular data. Until such information becomes available, and while we focus on other issues within Dadagulella gen. nov., we maintain the two species as separate. Van Bruggen (1986) took a similar approach with two other streptaxids, one described by Preston from the Shimba Hills, the other by Morelet from Mayotte.

There is a nomenclatural issue concerning the name minuscula Morelet, 1877. Morelet (1881) tried to replace the name used for the (1877) description, Pupa minuscula, with the name used for the (1877) figure, Ennea fischeriana. Morelet (1881) wrote that the name $P$. minuscula had been published in error. Subsequently both Tryon (1885: 100) and Kobelt (1905: 166; 1910: 158) accepted fischeriana as the species name. However, when revising the fauna of the Comoros, Fischer-Piette \& Vukadinovic (1974) disagreed. They treated E. fischeriana is an objective synonym of $P$. minuscula since the latter was not preoccupied and was validly introduced. This point of view was followed by Richardson (1988). As a consequence, the lectotype of $D$. m. minuscula comb. nov. in NHMUK also becomes the lectotype of E. fischeriana and the latter name remains unavailable for a taxon founded on another specimen. This includes the paralectotype, which is further discussed below.

Finally, we note that, although Emberton \& Pearce (2000) described a junior homonym of minuscula Morelet, 1877 in Gulella (G. minuscula Emberton \& Pearce, 2000) no replacement name is required since minuscula Morelet is here transferred from Gulella to Dadagulella gen. nov. 
Dadagulella minuscula mahorana subsp. nov.

Figs 40, 64, 84; Table 1

? Ennea (Uniplicaria) fischeriana "grössere Form auf Mayotte” - Kobelt 1905: 166.

\section{Etymology}

From English noun or adjective 'Mahoran', denoting a person or thing from Mayotte; Latinized by the addition of the feminine ending ' $-a$ ' and used as a noun in apposition.

\section{Type material examined}

MAYOTTE: holotype NMW.1955.158.25051: 1 ad., "Mayotte I.", standing as "fischeriana". Paratypes NMW.1955.158.25065: 2 ad., data as holotype.

\section{Type locality}

Mayotte (approx. $12.85^{\circ} \mathrm{S}, 45.15^{\circ} \mathrm{E}$ ), Comoros archipelago.

\section{Other material examined}

MAYOTTE: NHMUK.1882.5.27.6-7: 2 ad., "Mayotte" (approx. $12.85^{\circ} \mathrm{S}, 45.15^{\circ} \mathrm{E}$ ), standing as "fischeriana". NHMUK.20110171: 2 ad., "Mayotte", standing as "fischeriana". RMNH.MOL.273928: 1 ad., "Mayotte", standing as "fischeriana".

\section{Description}

SHELl (Figs 40, 64). Variable in size, shape and dentition, large $(4.30-4.60 \mathrm{~mm}$ high x 1.90-2.20 mm wide), of 6.5-7.5 whorls. Ovate-acuminate, spire narrowly acuminate to coeloconoid (spire angle 50$57^{\circ}$ ). Apex pointed. Embryonic whorls smoothly granulate. Subsequent whorls with finer, much more numerous ribs than the lectotype of D. r. radius comb. nov. (15-23 per $\mathrm{mm}$ on penultimate whorl). Sutures relatively deep. Umbilicus closed or nearly so. Peristome complete, or incomplete parietally. Outer palatal surface of aperture with a depression corresponding to the palatal tooth. Dentition 6-fold, consisting of: one lamella-like parietal tooth, sometimes slightly bifid; one slab-like palatal tooth, often bifid, but with parieto-palatal sinus barely present; one basal denticle; two shallow columellar denticles; and one deep-set columellar baffle, folded and sub-trifid, always visible. Shells and anatomy of juveniles unknown.

\section{Range and habitat}

Mayotte; habitat unknown.

\section{Remarks}

This Mayotte subspecies is here separated from its counterpart on Nzwani for the first time. Specimens of Dadagulella gen. nov. species from Mayotte were first discussed by Morelet (1881) under his proposed replacement name for Pupa minuscula (see above). He noted specimens from Mayotte were larger and had more complex dentition than those from Anjouan. Tryon (1885) and Kobelt (1905) followed Morelet in treating D. fischeriana (i.e. D. minuscula comb. nov. s.l.) as a variable species that was present on the "Comoros Islands" (Tryon 1885) or on Anjouan, with a "grössere Form auf Mayotte" (Kobelt 1905, although his dimensions of $9 \mathrm{~mm} \times 2 \mathrm{~mm}$ must be erroneous). Both authors appear to have copied Morelet's (1877) figure of the lectotype of D. m. minuscula comb. nov., unless they saw material very like it, and appear to have repeated (translated) Morelet's (1881) comments on dentition. Tryon (1885) says "sometimes the parietal lamina is accompanied by a more profound very small tooth" but this may be a misinterpretation of Morelet's (1881) "le pli pariétal peut être accompagné d'une très petite denticule plus profonde", with "plus profonde" meaning 'deeper', rather than 'profound', i.e. 
'more obvious' or 'more important'. Morelet's "denticule" is likely to refer to the bifid shape of the parietal tooth, rather than to an additional parietal denticle (like that of D. browni comb. nov. s.l.) which is not present in any of the specimens of D. minuscula comb. nov. s.l. we examined. It is not clear to which of the other teeth Morelet's (1881) "cinquième petite dent, dans la gorge de la coquille" refers, because all Mayotte specimens we examined have 6-fold dentition. It could even be the fifth tooth, i.e. the shallow columellar denticle, of the paralectotype of D. m. minuscula comb. nov., since Morelet (1881) is not explicit about the shell he is referring to. This raises another unfortunate possibility: that the paralectotype of $D . m$. minuscula comb. nov., apparently from Anjouan, was in fact a specimen without type status that was added later, and may even have come from Mayotte (or elsewhere), which would accord with Morelet's (1881) amendments to his description. However, we have no other reason to doubt the existing labels.

We here introduce the name D. m. mahorana subsp. nov. for the larger, coeloconoid specimens from Mayotte, the name fischeriana Morelet being unavailable (see above). They are indeed larger than the two specimens of D. m. minuscula comb. nov. (the size ranges do not overlap), are more elongate, have a more coeloconoid spire, finer and more numerous ribs, and 6-fold dentition including two shallow columellar denticles. These same features also distinguish them from D. radius comb. nov. s.l., which they overlap in size but only barely in the higher number of ribs per millimetre. Although as with $D$. radius comb. nov. s.l., it is difficult to distinguish intra- and interspecific variability, it is clear that the differences between the holotype of D. m. mahorana subsp. nov. and the lectotype of D. m. minuscula comb. nov., each collected on different islands, are substantial and sufficient for most modern authors to consider them distinct species. Alternatively, and given the residual uncertainty about the paralectotype of D. m. minuscula comb. nov., they may form part of a complex of subspecies. Again, further data is needed to address this.

Dadagulella rondoensis (Verdcourt, 1994) comb. nov. Figs 41, 84; Table 1

Gulella rondoensis Verdcourt, 1994: 137-139, fig. 1.

Gulella rondoensis - Verdcourt 2006: 48.

\section{Type material examined}

TANZANIA: holotype SMF.310150: 1 ad., Rondo Forest Reserve, Rondo Plateau, Lindi District $\left(10.12^{\circ} \mathrm{S}, 39.22^{\circ} \mathrm{E}\right)$, evergreen forest with Milicia Sim, Albizia Durazz., Dialium L., etc. in small gully and amphitheatre around a well on escarpment, $650 \mathrm{~m}$ alt., leg. Bidgood, Abdallah \& Vollesen, 10 Feb. 1991 (examined digital photograph only).

\section{Other material examined}

None.

\section{Description}

SHELl (Fig. 41). Large (4.10 mm high x $2.20 \mathrm{~mm}$ wide), of 6.25 whorls. Subconical (maximum width being in bottom third of the shell, at body whorl). Spire narrowly acuminate, almost cyrtoconoid (convex) rather than coeloconoid (spire angle $52^{\circ}$ ). Apex sharply pointed. Embryonic whorls punctate or malleate, rather than merely granulate. Later whorls with relatively fine ribs (about 14 per $\mathrm{mm}$ on penultimate whorl). Sutures of intermediate depth. Umbilicus narrowly open. Peristome incomplete parietally. Dentition weak, 3-fold (although could be interpreted as 2-fold), consisting of: one lamellalike parietal tooth, with a swelling above it that recalls the one in D. conoidea; one weak palatal tooth, not forming a parieto-palatal sinus; and one very weak, shallow columellar swelling. Further minute 
swellings just perceptible in the holotype (Fig. 41) were not noted by Verdcourt (1994) who interpreted the dentition as 2-fold. Shells and anatomy of juveniles unknown.

\section{Range and habitat}

Forest at the type locality, southeastern Tanzania.

\section{Remarks}

This species differs from $D$. conoidea comb. nov. in its weaker dentition, smaller size, and in having punctate apical whorls. Along with $D$. conoidea comb. nov. and $D$. delta sp. nov. it has weaker dentition than other Dadagulella gen. nov. However, both D. rondoensis comb. nov. and D. conoidea comb. nov. are distinctively more conical, i.e. less ovate than other Dadagulella gen. nov. These two are attributed to the genus somewhat speculatively, on the basis of their acuminate spire and pointed apex. These features mean they do not obviously fit into Gulella or any of its named subgenera, or indeed other plausible streptaxid genera. No anatomical or juvenile shell data are available for either species, both being known from single specimens. The punctuate apex of D. rondoensis comb. nov., unique in Dadagulella

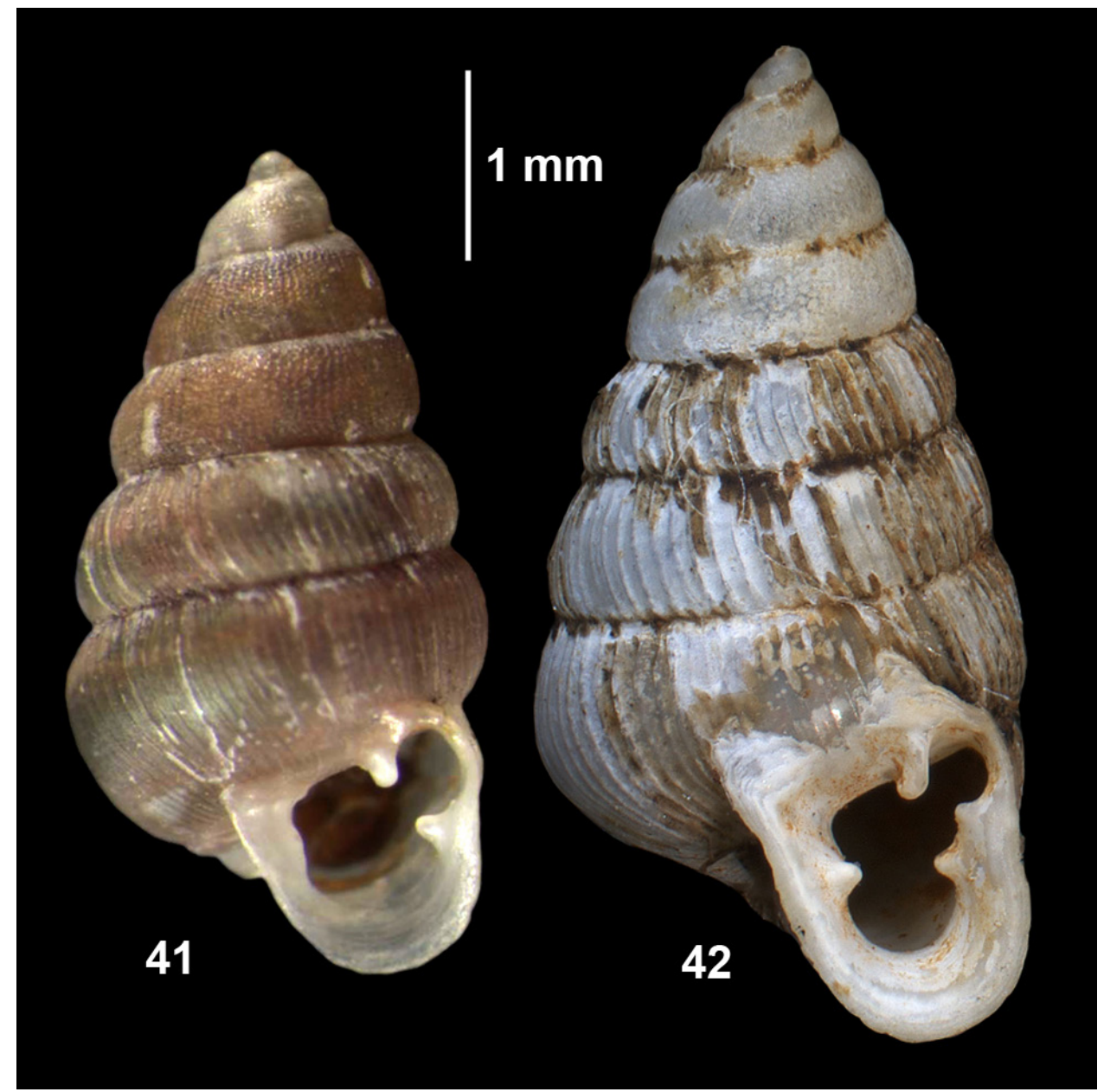

Figs 41-42. Adult shells of Dadagulella gen. nov. species. 41. D. rondoensis (Verdcourt, 1994) comb. nov., holotype, Rondo (photo by R. Janssen). 42. D. conoidea comb. nov., holotype, Kwamgumi (after Verdcourt 1996). 
gen. nov., may not be significant in this respect (see Rowson 2007b for a discussion on the value of apical sculpture in distinguishing African streptaxid genera). The apex of D. conoidea comb. nov. is less obviously punctuate, although it may have been worn smooth (Verdcourt 1996). In the description of D. rondoensis comb. nov., Verdcourt (1994) discussed a resemblance only to Gulella galactochila (Crosse, 1885), a much larger and more broadly acuminate Tanzanian species that we consider to lack the characteristic features of Dadagulella gen. nov. Although G. galactochila has not been dissected, the anatomy of another species very similar to it (G. udzungwensis van Bruggen, 2003) lacks the anatomical features of Dadagulella gen. nov. (Rowson unpublished). In his discussion of D. conoidea comb. nov., Verdcourt (1996) made no reference to either D. rondoensis comb. nov. or G. galactochila, but only to two species that we here treat in Dadagulella gen. nov. (D. r. radius comb. nov. and D. cuspidata comb. nov.). We contend firstly that D. rondoensis comb. nov. and D. conoidea comb. nov. are more similar to one another than either is to G. galactochila, and secondly that the resemblance between $D$. conoidea comb. nov., D. $r$ radius comb. nov. and $D$. cuspidata comb. nov. extends also to $D$. rondoensis comb. nov.. Our attribution of them to Dadagulella gen. nov. reflects this point of view.

Dadagulella conoidea (Verdcourt, 1996) comb. nov.

Figs 42, 84; Table 1

Gulella conoidea Verdcourt, 1996: 135-137, fig. 1.

Gulella conoidea - Tattersfield 1998b: 37. — Verdcourt 2006: 48.

\section{Type material examined}

TANZANIA: Holotype RMNH.MOL.57150: 1 ad., East Usambara foothills, Kwamgumi/Segoma Reserve, about $4.57^{\circ}-4.58^{\circ} \mathrm{S}, 38.43^{\circ}-38.45^{\circ} \mathrm{E}$, near Muzi R./Sigi R. junction, leg. Frontier Tanzania (examined digital photograph only).

\section{Other material examined}

None.

\section{Description}

SHeLl (Fig. 42). Large (5.5 mm high x $2.80 \mathrm{~mm}$ wide), of 8.0 whorls. Subconical (maximum width being in bottom third of the shell, at body whorl). Spire narrowly acuminate, almost cyrtoconoid (convex) rather than coeloconoid (spire angle $48^{\circ}$ ). Apex sharply pointed. Embryonic whorls "probably smooth but worn" (Verdcourt 1996). Later whorls with relatively weak ribs (about 11 per mm on penultimate whorl). Sutures relatively shallow. Umbilicus narrowly open. Peristome incomplete parietally, or nearly so. Dentition 3-fold (although could be interpreted as 4-fold), consisting of: one lamella-like parietal tooth, with a swelling above it that recalls that in D. rondoensis comb. nov.; one strongly bifid palatal tooth (or pair of teeth), not forming a parieto-palatal sinus; and a shallow columellar tooth or denticle. Shells and anatomy of juveniles unknown.

\section{Range and habitat}

Altitude and habitat not stated but probably in lowland forest at approximately $200 \mathrm{~m}$ at the type locality, northeastern Tanzania. Another species (D. radius comb. nov.) also occurs at Kwamgumi.

\section{Remarks}

See D. rondoensis comb. nov. above. 


\section{Key to species and subspecies (adult shells)}

1. Dentition simple, 2-fold to 4-fold (Figs 35, 38, 41, 42, 51, 56, 62), never including a parietal denticle to the left of parietal tooth 2

- Dentition complex, 5-fold to 8-fold (Figs 52-55, 57-61, 63, 64) (if in doubt key from here) ......... 8

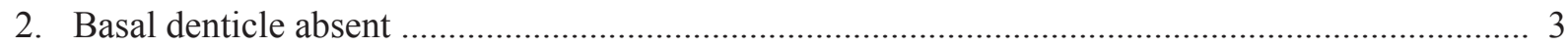

- Basal denticle present (may be partly or wholly hidden behind palatal tooth, e.g. Fig. 56, so if alternative fails return here)

3. Shell small (up to $3.1 \mathrm{~mm}$ high) with very fine, very numerous ribs (about 27 per mm on penultimate whorl) (Fig. 37)

D. meredithae (van Bruggen, 2000) comb. nov.

- Shell large (4.1-5.5 mm high) and with 13 or fewer ribs per mm on penultimate whorl (Figs 35, 4142)

4. Shell ovate-acuminate (maximum width approximately at middle of shell); spire broadly acuminate (spire angle $56^{\circ}$ or more); ribs sinuous (Fig. 35)

D. delta sp. nov.

- Shell subconical (maximum width in bottom third of shell); spire narrowly acuminate (spire angle $52^{\circ}$ or less); ribs not sinuous (Figs 41-42)

5. One palatal tooth, columellar dentition weak or absent; $4.10 \mathrm{~mm}$ high (Fig. 41)

D. rondoensis (Verdcourt, 1994) comb. nov.

- Two palatal teeth; one strong shallow columellar tooth; $5.5 \mathrm{~mm}$ high (Fig. 42)

D. conoidea (Verdcourt, 1996) comb. nov.

6. Deep-set columellar baffle clearly visible through aperture (if not so clearly visible, then apex pointed and not rounded) (e.g. Figs 51-57, 62-64)

- Columellar baffle barely visible through aperture; apex rounded (Taita Hills, Kenya) (Fig. 33) ......

D. nictitans (Rowson \& Lange, 2007) comb. nov.

7. No columellar dentition other than deep-set baffle; basal denticle present, either completely hidden by a slab-like palatal tooth or visible only when shell is turned (Kimboza, Uluguru Mts, Tanzania) (Figs 28, 56)

D. ecclesiola sp. nov.

- Usually with shallow columellar dentition as well as deep-set baffle; basal denticle clearly visible in normal apertural view

8. Parietal tooth strongly V-shaped, flaring, directed outwards; three palatal teeth; shell of 5.0 or fewer whorls (Figs 34, 61)

D. frontierarum sp. nov.

- Shell without this combination of characters 9

9. Upper shallow columellar tooth strong, squarish, projecting into aperture as far or further than any deeper columellar baffle (Figs 30-31, 36, 58-59)

- Shallow columellar dentition projecting less far into aperture than any deeper columellar baffle (Figs 51-57, 60-64)

10. Apex rounded; spire broadly acuminate, spire angle $70^{\circ}$; ribs weak, almost disappearing in the middle of the whorl (Virunga NP, DR Congo) (Fig. 36)

D. selene (van Bruggen \& Van Goethem, 1999) comb. nov.

- Apex sharply pointed; spire acuminate or coeloconoid, spire angle $65^{\circ}$ or less; ribs prominent, running from suture to suture; apex finely radially striate in fresh specimens (Figs 30-31) .......... 11 
11. Shell more than $4.0 \mathrm{~mm}$ high; parietal tooth simple, lamella-like; two palatal teeth (W. Usambara Mts, Tanzania) (Figs 31, 59)

D. cuspidata (Verdcourt, 1962) comb. nov.

- Shell up to $4.0 \mathrm{~mm}$ high; parietal tooth V-shaped; one palatal tooth (elsewhere in Tanzania) (Figs 30, 58)

D. minareta sp. nov.

12. Outer palatal surface of aperture with very deep, long, furrow-like depression; basal denticle absent or not visible in apertural view (Figs 29, 33, 57)

- Outer palatal surface of aperture with shallow, not furrow-like depression; basal denticle clearly visible in apertural view

13. Apex sharply pointed; spire coeloconoid (Ngorongoro, Tanzania) (Figs 29, 57) .. D. cresswelli sp. nov.

- Apex rounded (Taita Hills, Kenya) (Fig. 33) ..... D. nictitans (Rowson \& Lange, 2007) comb. nov.

14. Sculpture of widely-spaced, flaring, subtriangular, lamella-like ribs; spire narrowly acuminate (spire angle $\left.<50^{\circ}\right)($ Cabo Delgado, Mozambique) (Fig. 27) ........ D. delgada (Muratov, 2010) comb. nov.

- Shell without this combination of characters 15

15. Shell 4.8 mm-5.5 mm high (Pemba I., Tanzania) (Figs 32, 60)

D. pembensis sp. nov.

- Shell up to $4.6 \mathrm{~mm}$ high 16

16. Shell up to $3.3 \mathrm{~mm}$ high; parieto-palatal sinus narrow, appearing parallel-sided in apertural view; nearly always with an additional, small parietal denticle to the left of parietal lamella; nearly always with two basal denticles (Figs 21-26, 54-55) ... 17 (D. browni (van Bruggen, 1969) comb. nov. s.l.)

- Shell up to $4.6 \mathrm{~mm}$ high; parieto-palatal sinus wide, not parallel-sided in apertural view; always without a small parietal denticle to the left of parietal lamella, even if shell less than $3.3 \mathrm{~mm}$ high

17. Only one basal denticle present; no columellar dentition other than a deep-set baffle (Mafia I., Tanzania) (Figs 21, 54)

D. browni mafiensis subsp. nov.

- Two basal denticles almost always present; one or two columellar denticles present in addition to a deep-set baffle (Figs 22-26, 55)

18. Shell 3.15-3.25 mm high; sutures relatively shallow; peristome complete; parieto-palatal sinus longer and narrower, not widening appreciably towards its inner end (Semuliki NP, Uganda) (Figs 22, 55; compare with Figs 23-26)

D. browni semulikiensis subsp. nov.

- Shell (2.55-3.20 mm high; sutures relatively deep; peristome incomplete parietally; parieto-palatal sinus shorter and broader, widening towards its inner end (South Africa, Mozambique, S. Tanzania) (Figs 23-26; compare with Figs 22, 55)

D. browni browni (van Bruggen, 1969) comb. nov.

19. Sculpture of numerous, fine ribs (15 or more per mm on penultimate whorl); spire coeloconoid, elongate (Mayotte) (Figs 40, 64)

D. minuscula mahorana subsp. nov.

- Shell without this combination of characters (e.g. Figs 1-20, 38-39) 20

20. Shell $4.0 \mathrm{~mm}$ or more high, sculpture of few, coarse, widely-spaced ribs (5-10 per mm on penultimate whorl); dentition 4-fold to 5-fold (Taru Desert and elsewhere in SE Kenya) (Figs 6-8, 51) ....

D. radius calva (Connolly, 1922) comb. et stat. nov.

- Shell without this combination of characters 21

21. Dentition 5-fold or more, although when shallow columellar dentition is weak, might be considered 4-fold (lowlands of SE. Kenya and NE. Tanzania) (Figs 1-5, 9-20, 52-53)

D. radius radius (Preston, 1910) comb. nov.

- Dentition 4-fold, lacking a shallow columellar tooth (as in the lectotype) or 5-fold, with a shallow columellar tooth (as in the paralectotype) (Nzwani [Anjouan] I., Comoros) (Figs 38-39, 62-63) ..... 


\section{Discussion}

\section{Shell}

The shells of Dadagulella gen. nov. differ from those of Gulella s.l. in the acuminate (sometimes coeloconoid or cyrtoconoid) spire; the majority also has a much more pointed apex. They are never smooth, unlike many Gulella. Patterns of adult apertural dentition that are superficially similar to those of Dadagulella gen. nov. species occur in some Gulella, especially where the dentition is simple, but not in combination with the above mentioned features. A possible exception is the South African $G$. contingens Burnup, 1925 which has an acuminate spire but rounded apex (I.V. Muratov 2012, pers. comm.). It may prove to belong to Dadagulella gen. nov. The shells of juvenile Dadagulella gen. nov. are almost always dentate, while those of juvenile Gulella are very rarely so. Two species of Gulella s.l.

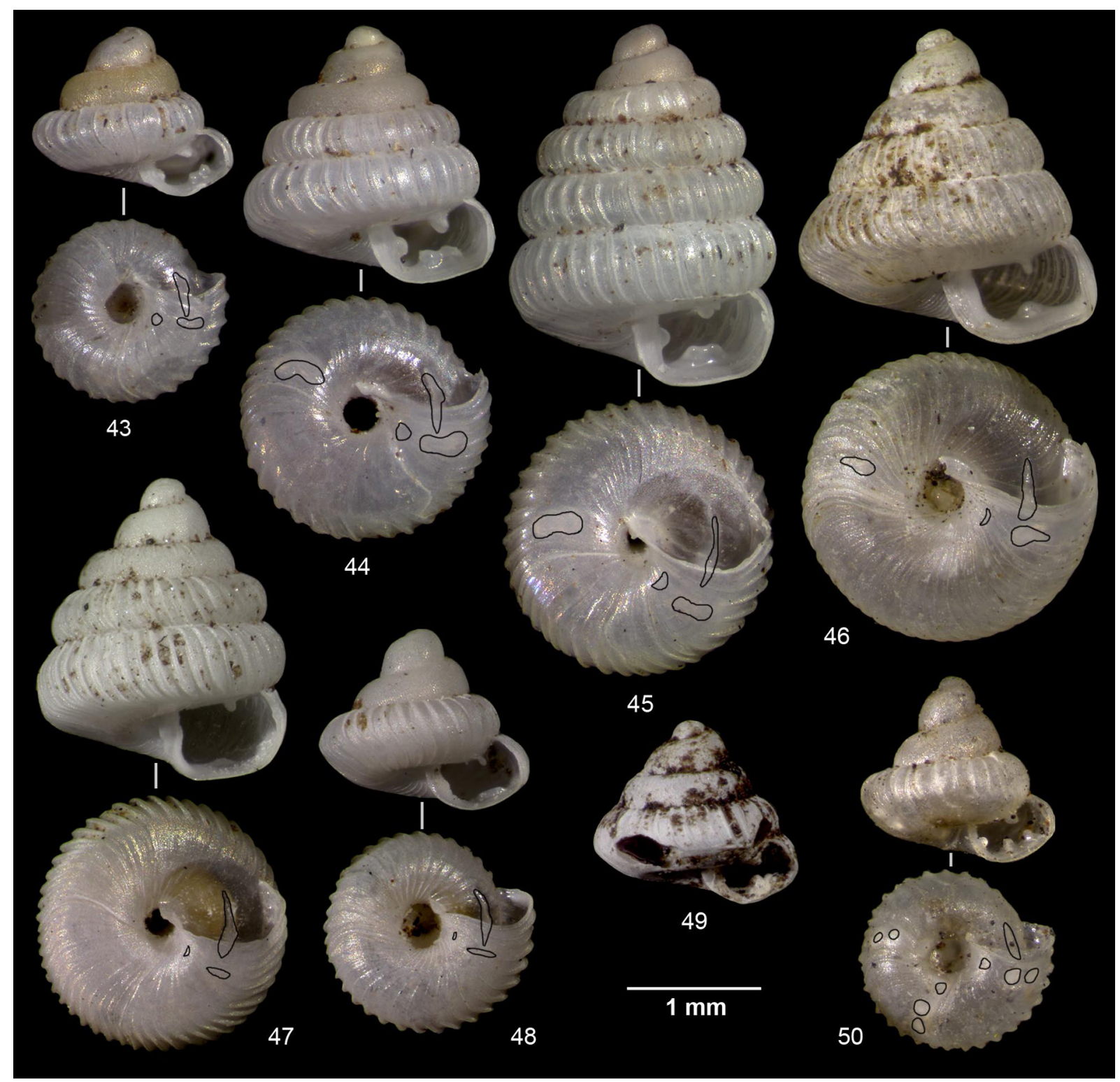

Figs 43-50. Juvenile shells of Dadagulella gen. nov. species, with dentition emphasized in basal view including earlier dentition visible through the shell. 43-45. D. radius radius, Mbudya I. 46. D. pembensis sp. nov., Ngezi. 47-48. D. browni browni, Mwanihana. 49. ? D. ecclesiola sp. nov., Kimboza. 50. D. minareta sp. nov., Kimboza. 
with dentate juveniles, the Tanzanian G. subringens (Crosse, 1886) and the South African G. phyllisae Burnup, 1925 have been shown not to belong to Dadagulella gen. nov. by sequencing (Rowson et al. 2010a; Rowson \& Herbert, unpublished). The shells of Dadagulella gen. nov. do not correspond to those of any other existing streptaxid genus or subgenus. They differ from those of the Central-West African Conogulella Pilsbry, 1919 in having a more acuminate spire and more pointed apex, in lacking strong spiral striae on the apical whorls, and in dentition. Moreover, juvenile Conogulella lack apertural dentition (A.J. de Winter 2012, pers. comm.). Dadagulella selene comb. nov., a species with a more rounded apex and apical whorls with "a hint of spiral engraving", deserves further investigation from this perspective although its authors (van Bruggen \& Van Goethem 1999) considered it part of the same group as D. browni comb. nov.. Another Central-West African genus, Costigulella Pilsbry, 1919 has dentate juveniles (de Winter 2008) but is otherwise unlike Dadagulella gen. nov. A further species from the central Congo basin, Ptychotrema (Nsendwea) nobrei Dupuis \& Putzeys, 1923 (sole species
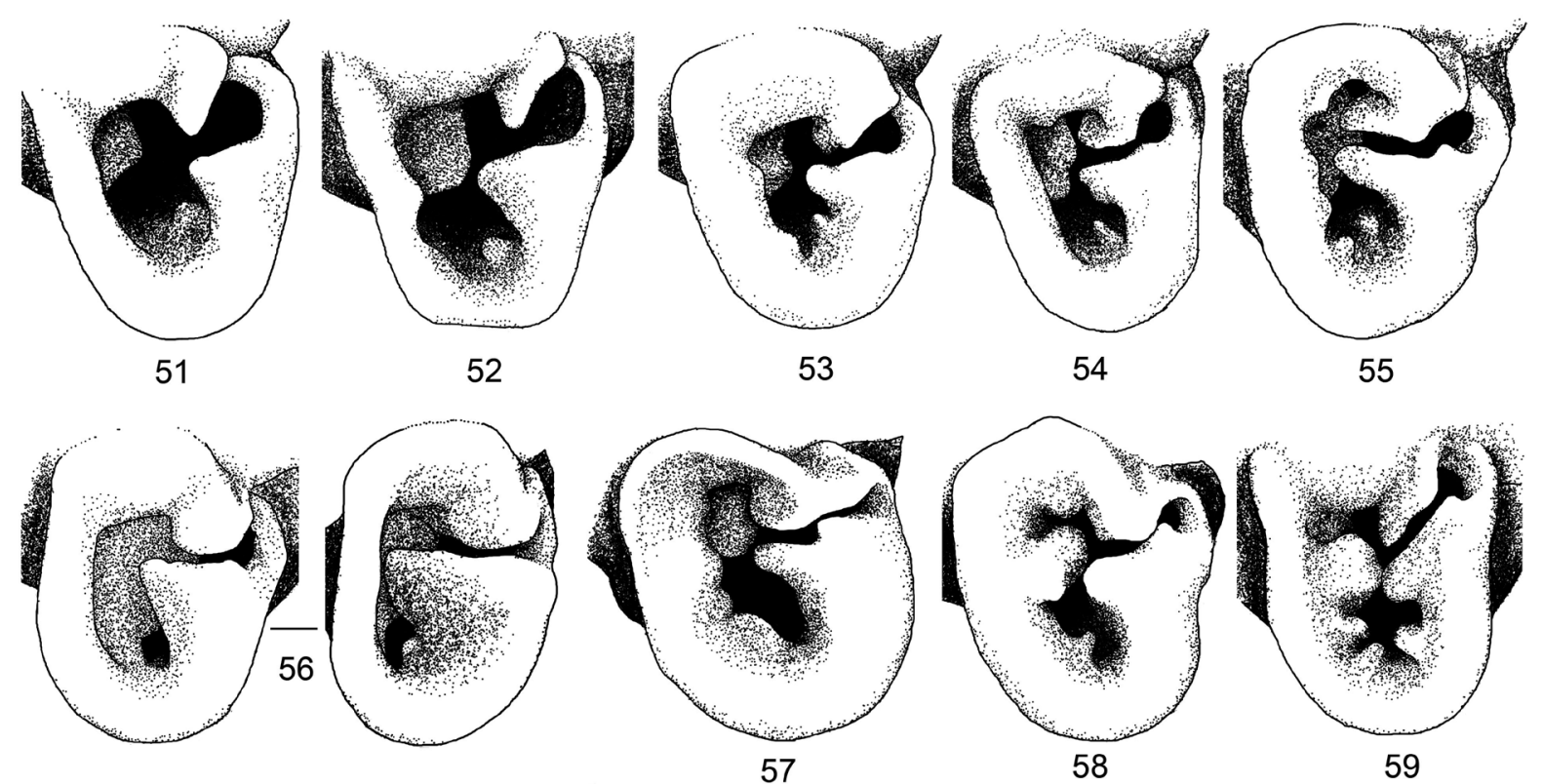

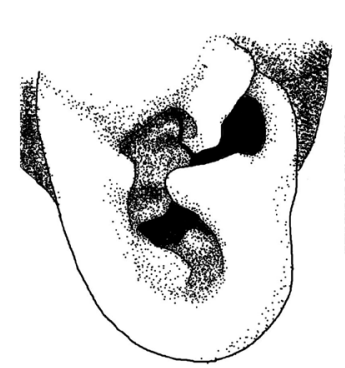

60

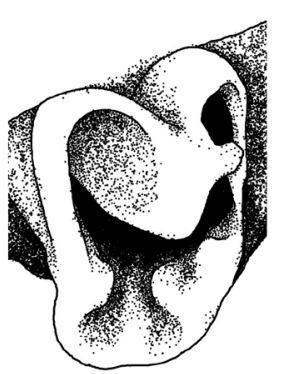

61

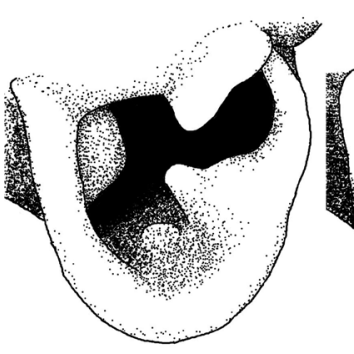

62

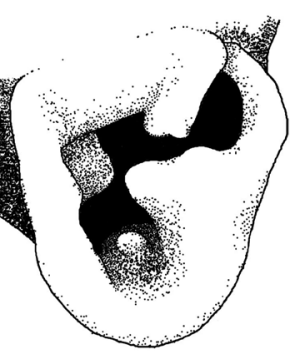

63

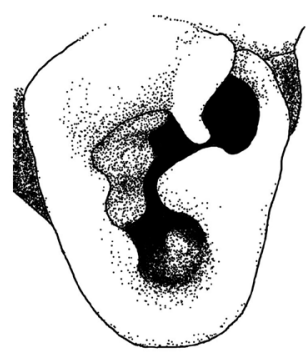

64

Figs 51-64. Apertures of adult shells of Dadagulella gen. nov. species (not to scale). 51. D. radius calva, lectotype, Taru Desert. 52. D. radius radius, lectotype, Shimba Hills. 53. D. radius radius, Amboni. 54. D. browni mafiensis subsp. nov., holotype, Mlula. 55. D. browni semulikiensis subsp. nov., holotype, Semuliki NP. 56. D. ecclesiola sp. nov., holotype, Kimboza (two views of shell showing basal tooth only visible when shell angled). 57. D. cresswelli sp. nov., holotype, Ngorongoro. 58. D. minareta sp. nov., holotype, Kimboza. 59. D. cuspidata comb. nov., holotype, Shume (note shell angled slightly differently to that in Fig. 31). 60. D. pembensis sp. nov., holotype, Ngezi. 61. D. frontierarum sp. nov., holotype, Mtai. 62. D. minuscula minuscula, lectotype, Nzwani. 63. D. minuscula minuscula, paralectotype, Nzwani. 64. D. minuscula mahorana subsp. nov., holotype, Mayotte. 
of Nsendwea Dupuis \& Putzeys, 1923) superficially resembles some Dadagulella gen. nov. in size and in its broadly conical spire. However, we agree with Adam et al. (1995) and Schileyko (2000) that its other shell features, including the inrunning palatal fold, support its classification among the subgenera of Ptychotrema L. Pfeiffer, 1853. Other Ptychotrema can likewise be distinguished from Dadagulella gen. nov. by these folds. Finally, juvenile Dadagulella gen. nov. are distinct from the East African Juventigulella Tattersfield, 1998, with which they occur at several Tanzanian sites (Tattersfield 1998b) in lacking the downturned aperture of adult Juventigulella.

\section{Salivary glands}

The shape of Dadagulella's salivary glands differs from that of the type species of Gulella in which the united gland is not appreciably divided into two lobes (Rowson \& Herbert, unpublished).

\section{Radula}

Dadagulella gen. nov. is highly unusual among Streptaxidae in having multicuspid radular teeth. Aiken (1981) believed the contrast between the radula of D. browni comb. nov. and of all other South African Gulella he studied was indicative of a difference in diet. The only prior reports of multicuspid streptaxid radulae appear to be Connolly (1930) and Verdcourt (1953) (see also Verdcourt 1990). Connolly (1930)

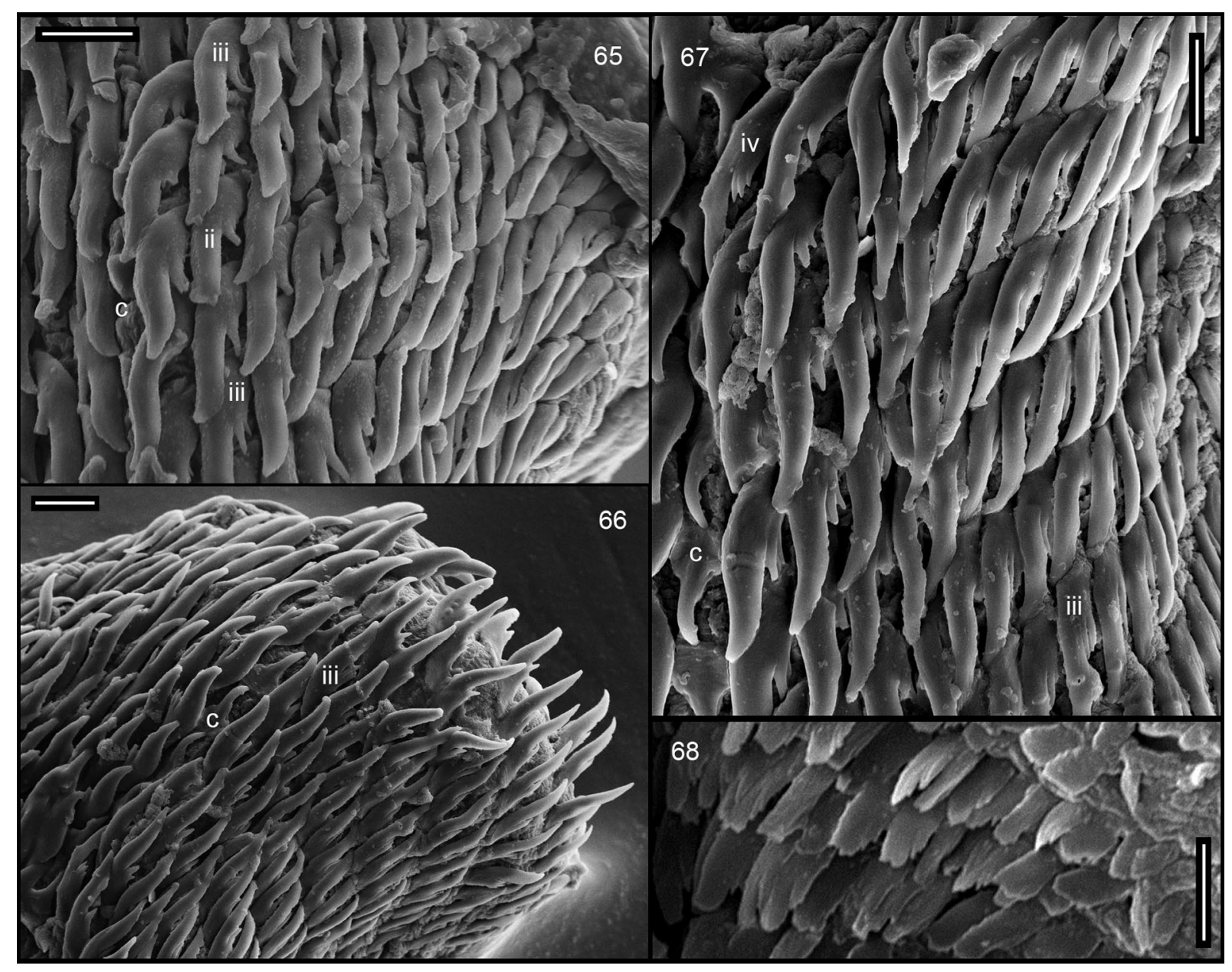

Figs 65-68. Radulae of Dadagulella gen. nov. species. 65. D. radius radius, Amboni. 66. D. pembensis sp. nov., Ngezi, radula in situ on odontophore, ventral view. 67. $D$. pembensis sp. nov., Ngezi. 68. $D$. pembensis sp. nov., Ngezi, teeth from ventral end of radular ribbon. Abbreviations: $\mathrm{c}=$ central tooth; ii, iii, and iv $=$ examples of bi-, tri- and quadricuspid teeth respectively. All scalebars $=10 \mu \mathrm{m}$. 


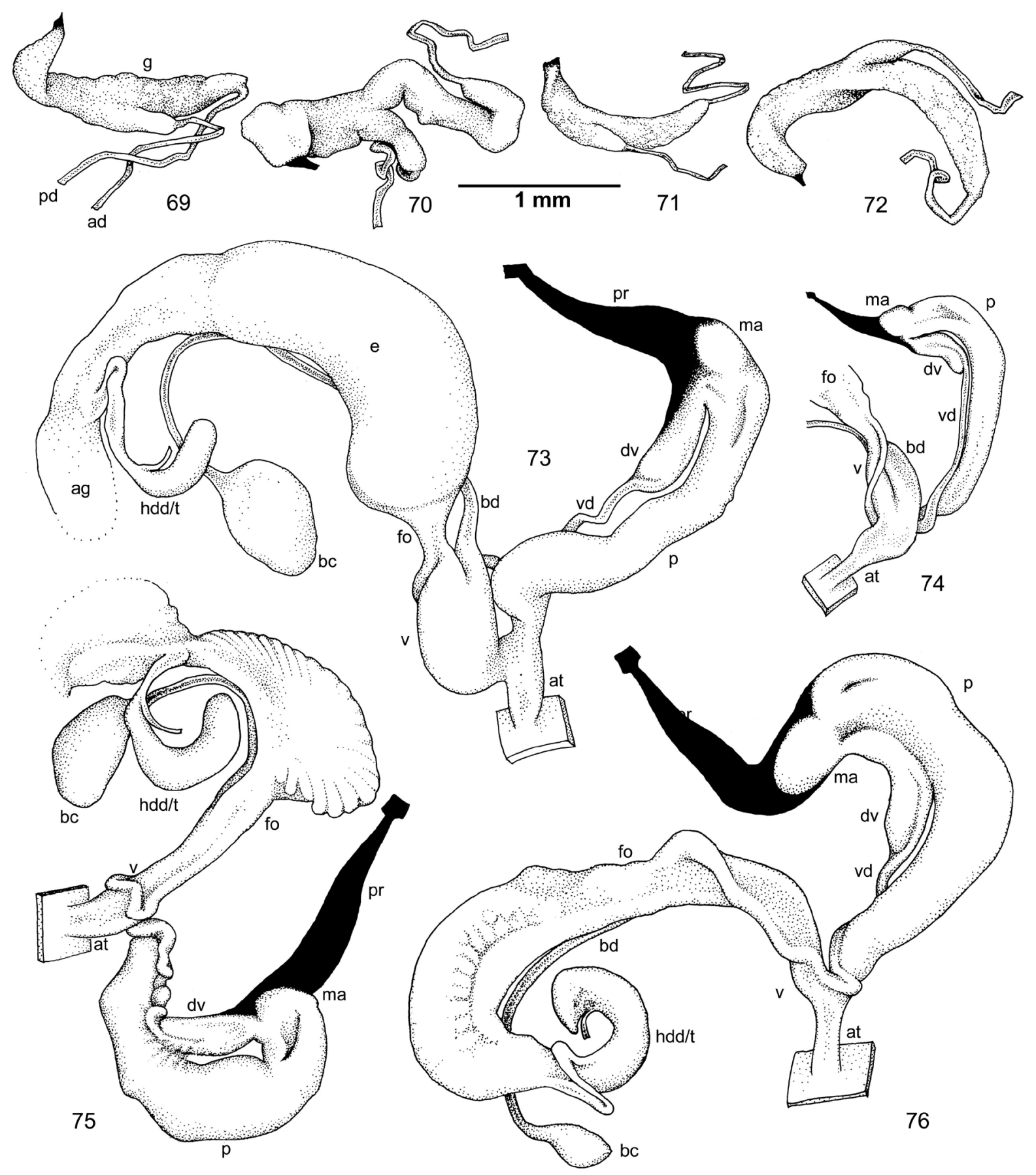

Figs 69-76. Salivary glands and genitalia of Dadagulella gen. nov. species. 69. D. radius radius, Amboni. 70. D. pembensis sp. nov., Ngezi. 71. D. browni browni, Kosi Bay. 72. D. delta sp. nov., Mwanihana. 73. D. radius radius, Amboni. 74. D. browni browni, Kosi Bay. 75. D. pembensis sp. nov., Ngezi. 76. $D$. delta sp. nov., Mwanihana. Abbreviations: ad = anterior duct of salivary gland; ag = albumen gland; at = atrium; $b c=$ bursa copulatrix; $b d=$ bursa duct; $d v=$ diverticulum of vas deferens; $\mathrm{e}=$ egg; fo $=$ free oviduct; $\mathrm{hdd} / \mathrm{t}=$ hermaphroditic duct diverticulum / talon; ma $=$ muscular apex; $\mathrm{p}=$ penis; $\mathrm{pd}=$ posterior duct of salivary gland; $\mathrm{pr}=$ penial retractor muscle; $\mathrm{v}=$ vagina; $\mathrm{vd}=$ vas deferens. 
described the radula of the Ugandan Conogulella conospira subsp. polynematica (Pilsbry, 1919) as consisting of evenly bicuspid teeth (formula 47-1-47); this is also seen in other Conogulella species, the cusps being nearly equal in size (A.J. de Winter 2012, pers. comm.). Verdcourt (1953) described the radula of the Tanzanian Gulella usambarica (Craven, 1880) as consisting almost entirely of multicuspid teeth (formula 26-1-26); again, the cusps are nearly equal in size. Sequence data (Rowson et al. 2010a) show that Dadagulella gen. nov. is only distantly related to G. usambarica. Thus a relationship between Dadagulella gen. nov. and Conogulella based on the multicuspid radula cannot be ruled out, but remains unproven since multicuspid teeth occur in distantly related lineages.

\section{Genitalia}

Dadagulella gen. nov. differs from the type species of Gulella (Rowson \& Herbert, unpublished) in having a swelling of or diverticulum on the vas deferens, a muscular apex, an apical penial "scoop" and one or more large apical penial hooks, and a smaller number of penial hooks in total. The genitalia differ

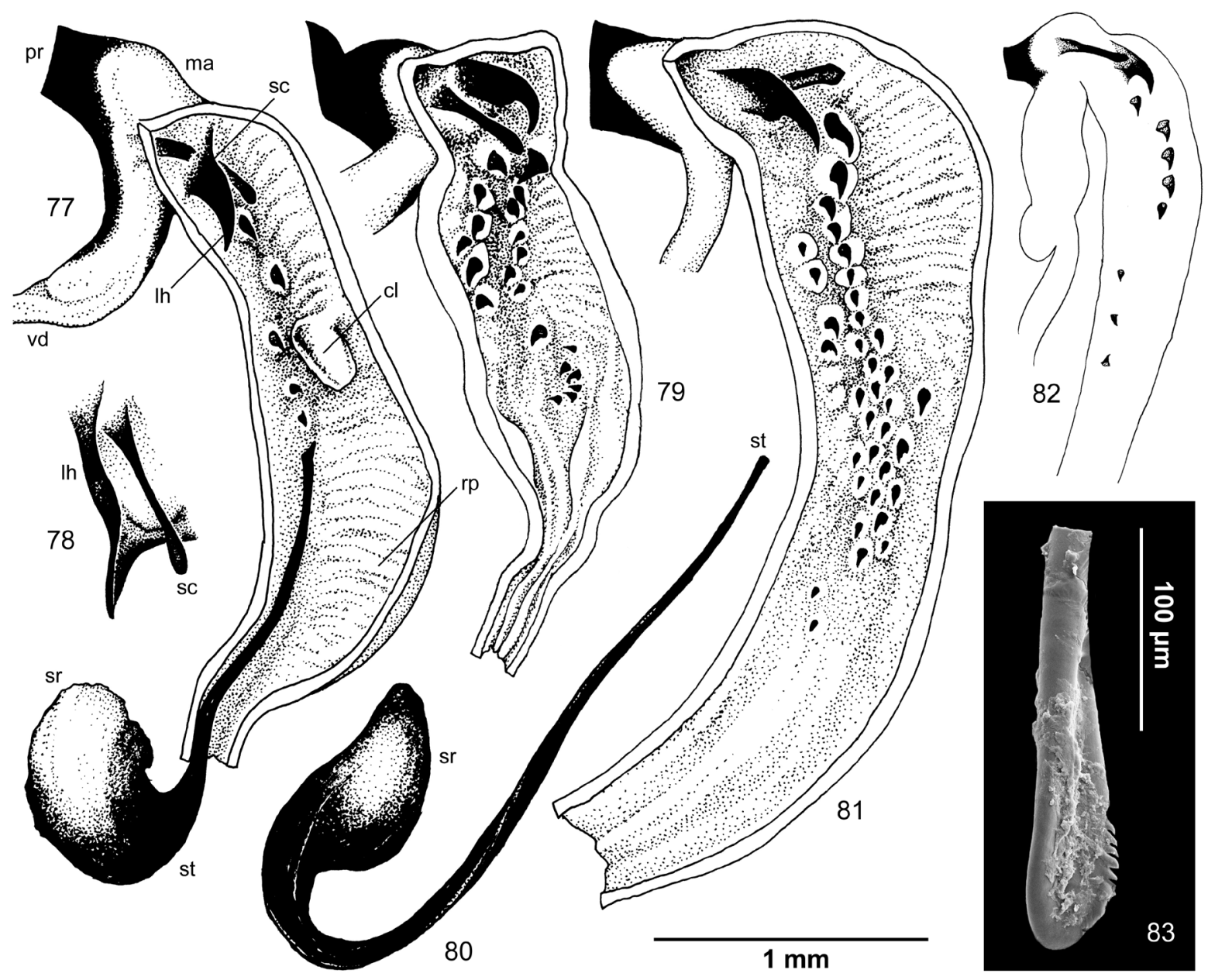

Figs 77-83. Penes and spermatophores of Dadagulella gen. nov. species. 77. D. radius radius, Amboni, penis with spermatophore in situ. 78. Same, hook and scoop in situ when hook lifted back to expose scoop. 79. D. pembensis sp. nov., Ngezi, penis. 80, same, spermatophore from penis of another individual. 81. D. delta, Mwanihana, penis. 82. D. browni browni, Kosi Bay, penis (diagrammatic). 83. D. radius crassa, Amboni, scoop magnified to show serrated edge. Abbreviations: $\mathrm{cl}=$ chitinized lobe; $\mathrm{l} \mathrm{h}=$ large apical hook; $\mathrm{ma}=$ muscular apex; $\mathrm{pr}=$ penial retractor muscle; $\mathrm{sc}=$ apical scoop; $\mathrm{st}=$ spermatophore tail; $\mathrm{sr}=$ spermatophore reservoir; $\mathrm{vd}=$ vas deferens. 
from those of Conogulella (A.J. de Winter 2012, pers. comm.) and many other West African species currently attributed to Gulella or its subgenera (Degner 1934; Schileyko 2000) in the same respects. The observation of "spermatophores" in the penis is unusual in Streptaxidae. The only prreviously published report appears to be de Winter et al. (1999), although similar structures have recently been found in the penes of other Gulella and former Gulella species (Rowson, unpublished; de Winter 2012, pers. comm.). It is not certain that the structures in Dadagulella gen. nov. are true spermatophores, especially if they are formed attached to the penial wall. Muratov (1999: 16) and Schileyko (2003: 1467) state that the somewhat similar structures in certain Trigonochlamydoidea Hesse, 1882 remain in the penis but empty their contents (perhaps a carbonate buffer; Muratov, 1999) into the partner's bursa. Muratov (1999) notes that their cavities cannot be filled with sperm without a connection to the epiphallus, but also that this does not rule out that Trigonochlamydoidea also produce true spermatophores. We note only that in $D$. pembensis sp. nov., the remains in the bursa resemble the tail of the structures found in the penis

\section{Molecular data}

The available DNA sequence data suggest that Dadagulella gen. nov. is a sister lineage to the one that contains Gulella, and that the two became separated in the Cenozoic (Rowson et al. 2010a). Further sequence data from additional species of Dadagulella gen. nov. and Gulella (Rowson \& Herbert unpublished), including the type species of Gulella (Herbert \& Rowson 2011), support the conclusion that the two lineages are separate, and that Gulella includes the type species of several nominal subgenera while Dadagulella gen. nov. does not. The two can be distinguished by the presence of an indel in the mitochondrial DNA sequence coding for COI (cytochrome oxidase I) in almost all Gulella species relative to Dadagulella gen. nov. (Rowson et al. 2010a; Rowson \& Herbert, unpublished). Another streptaxid species included in the "G. radius group" by van Bruggen $(1969,2000)$, the Kenyan $G$. pretiosa (Preston, 1911), has also been sequenced (Rowson et al. 2010a). It is clearly not closely related to either Dadagulella gen. nov. or Gulella itself, a finding also supported by anatomical data (Rowson unpublished).

\section{Fossil record}

There are many East African Miocene fossil taxa attributable to Gulella (e.g. Verdcourt 1963; Pickford 2009). It would be reasonable to expect Dadagulella gen. nov. to occur with them if the two had diverged by the Miocene. However, none appear to unambiguously show the features of Dadagulella gen. nov. Two species, G. leakeyi Verdcourt, 1963 and Gulella sp. C of Verdcourt 1963 from Rusinga resemble Dadagulella gen. nov. in their acuminate spires, and his figure 53 of $G$. sp. C (specimen 631/55) resembles $D$. radius comb. nov. but he does not discuss its affinities. The species G. moja Pickford, 2009 from Koru seems only superficially similar to Dadagulella gen. nov. All are from a part of East Africa from which no extant Dadagulella gen. nov. are known, although the distributions of other streptaxids found in the Rusinga and Koru deposits have evidently changed (Verdcourt 1963; Pickford 2009).

\section{Biogeography}

Dadagulella gen. nov. is evidently an eastern group that has not yet been recorded from West Africa or the Congo basin (Fig. 84). It currently appears most diverse in Tanzania and Kenya, with endemics in both highlands and lowlands. There are no records of Dadagulella gen. nov. from the volcanic highlands of central and northern Kenya, south-western Tanzania, or northern Tanzania, with the exception of D. cresswelli sp. nov. at Ngorongoro. Two species occur in the Albertine Rift region of endemism, but the group is otherwise unknown from the Guineo-Congolian forests of western Kenya or Uganda. This represents a disjunction of around $500 \mathrm{~km}$ across an area whose forest molluscs have been fairly wellstudied (e.g. Wronksi \& Hausdorf 2010; Tattersfield \& Rowson unpublished). In contrast, the genus occurs widely in eastern Kenya and central-eastern Tanzania, including throughout the famed Eastern Arc Mountains region of endemism, where eight species occur. Of these, six appear to be endemic 
to a single mountain range: Taita (D. nictitans comb. nov.); W. Usambara (D. cuspidata comb. nov.); E. Usambara (D. frontierarum sp. nov., $D$. conoidea comb. nov.); Uluguru (D. ecclesiola sp. nov.); and Udzungwa ( $D$. delta sp. nov.). These are all montane or submontane, occurring around or above $1000 \mathrm{~m}$ elevation, except for $D$. ecclesiola sp. nov. and D. conoidea comb. nov. which are found in the foothills. Endemics are not yet known from three other major Eastern Arc ranges: Nguru (D. minareta sp. nov. only), Mahenge (D. radius comb. nov. only) and Ukaguru (no Dadagulella gen. nov. recorded). The lowland $D$. radius comb. nov. s.l. is apparently replaced in some areas by other narrow-range endemics, namely $D$. pembensis sp. nov. or subspecies we attribute to $D$. browni comb. nov. s.l., which evidently ranges into southern Tanzania. However, in three places in Tanzania D. radius comb. nov. has been found in sympatry with other Dadagulella gen. nov. species. We take this in support of the hypothesis that such species are good genetic species rather than ecophenotypic variants. The apparent greater interpopulation variability seen in the lowland species $D$. radius comb. nov. s.l. and D. browni comb. nov. s.l. may reflect their wider ranges and the larger number of populations sampled. It remains possible that those populations most similar to typical $D$. radius comb. nov. form a complex of Pleistocene, incipient,

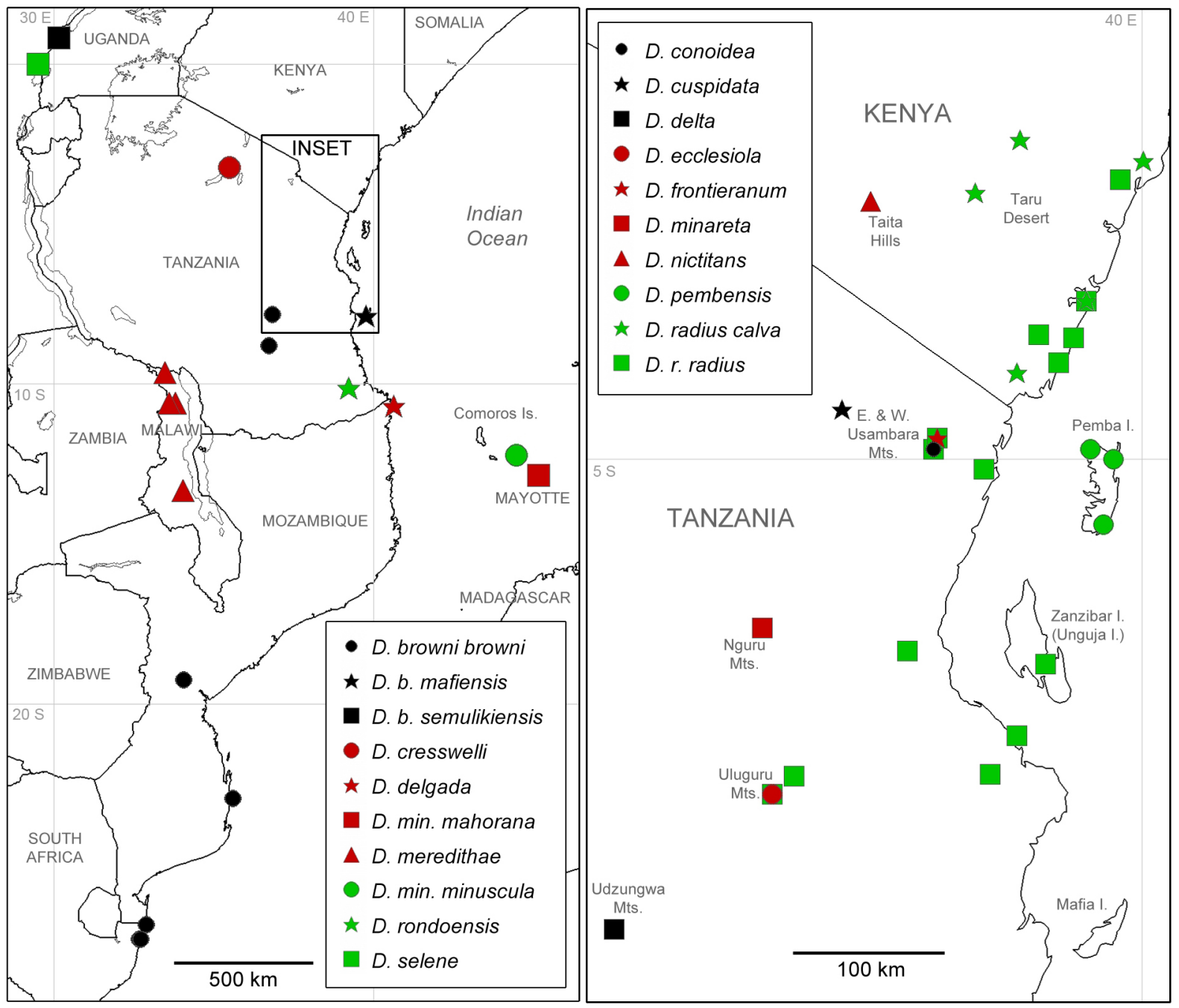

Fig. 84. Distribution of Dadagulella gen. nov. species, based on published records and material examined here (for additional records of D. meredithae comb. nov. in northern Malawi see van Bruggen 2000). The inset on the left corresponds to the map on the right. 
or hybridizing species, while the more distinctive populations (several of them montane endemics) are fully isolated species that separated earlier.

Beyond East Africa, Dadagulella gen. nov. is represented by at least one species in Malawi and Zambia, two in eastern Mozambique, one in eastern South Africa and one on the Comoros archipelago. The genus does not appear to have been found on Madagascar, although the genus Gulella s.l. is richly represented there (e.g. Emberton 2001). There is some shell resemblance between Dadagulella gen. nov. and the following Madagascan species: G. ambatovakiae Emberton, 2001; G. benjamini Emberton \& Pearce, 2000; G. hafa Emberton, 2001; G. hafahafa Emberton, 2001; G. mahafinaratra Emberton, 2001; G. manomboae Emberton, 2001; G. michellae Emberton, 2001; G. vakinifia Emberton, 2001 and G. vatosoa Emberton, 2001. This is a heterogenous group of species that does not key out together in the key of Emberton (2001). In each case the spire is acuminate, although slightly less so than in most Dadagulella gen. nov.. Juvenile teeth are not mentioned in the text of Emberton (2001) and a juvenile shell of one species (a paratype of $G$. hafahafa) is figured and appears to lack apertural teeth. The genitalia of G. benjamini were figured by Emberton \& Pearce (2000) and show an apical caecum and two longitudinal pilasters with a broad area between them. There is no apical scoop. The genitalia of G. reeae Emberton \& Pearce, 2000 in the same paper have a vas deferens and pilasters more typical of Gulella (Rowson \& Herbert unpublished). The anatomy of G. vatosoa is broadly identical to that of G. benjamini (unpubl. obs.). The anatomy of G. hafahafa, which is a Gulella based on sequence data (Rowson et al. 2010) is unlike that of G. benjamini or G. vatosoa in having few, larger hooks (unpubl. obs.) and unlike that of Dadagulella gen. nov. We conclude that Dadagulella gen. nov. as recognised here is not yet known from Madagascar. If Dadagulella gen. nov. and Gulella are indeed sister groups, these ibservations support an African, rather than Madagascan, divergence of the two.

\section{Acknowledgements}

We are grateful to A.J. de Winter (RMNH) for discussions and data on Conogulella, and photographs of RMNH specimens of Dadagulella gen. nov. We thank D.G. Herbert (NMSA) for generously providing material, J. Ablett (NHMUK), C.F. Ngereza (NMT), J. Slapcinsky (Florida Museum of Natural History, USA), D. Van den Spiegel and D. De Bakker (MRAC) for lending material and R. Janssen (SMF) for the photograph of D. rondoensis comb. nov. Comments from I.V. Muratov (NMSA), D.G. Herbert and an anonymous referee helped to improve the manuscript.

\section{References}

Adam W., van Bruggen A.C. \& Van Goethem J.L. 1995. Etudes sur les mollusques terrestres de l'Afrique, à partir des notes de feu le Dr. William Adam. 3. Ptychotrema (Ptychotrema s.s., Adjua, Excisa, Mirellia, Nsendwea, Ptychoon, Sphinctostrema) (Gastropoda Pulmonata: Streptaxidae). Bulletin de l'Institut Royal des Sciences Naturelles de Belgique, Biologie 65: 89-115.

Aiken D.W. 1981. Differentiation of the radula of South African species of Gulella into three types. Journal of Conchology 30 (5): 317-324.

Bruggen A.C. van 1969. Studies on the land molluscs of Zululand, with notes on the distribution of land molluscs in Southern Africa. Zoologische Verhandelingen 103: 3-116.

Bruggen A.C. van 1975. Streptaxidae (Mollusca, Gastropoda: Pulmonata) from Aldabra Island, Western Indian Ocean. Bulletin of the British Museum (Natural History) Zoology 28: 157-175.

Bruggen A.C. van 1986. Additional notes on Gulella (Gastropoda Pulmonata: Streptaxidae) from the Aldabra group, western Indian Ocean. Basteria 50: 71-77.

Bruggen A.C. van. 2000. Studies on the Streptaxidae (Mollusca: Gastropoda Pulmonata) of Malawii. 5. Description of Gulella meredithae spec. nov. Zoologische Mededelingen 74 (15): 225-235. 
Bruggen A.C. van 2003. Gulella udzungwensis spec. nov. (Gastropoda, Pulmonata, Streptaxidae), a new species from the Udzungwa Mountains in Tanzania. Basteria 67 (1-3): 87-90.

Bruggen A.C. van \& Appleton C.C. 1977. Studies on the ecology and systematics of the terrestrial molluscs of the Lake Sibaya area of Zululand, South Africa. Zoologische Verhandelingen 154: 3-44, pls. 1-4.

Bruggen A.C. van \& Meredith H.M. 1984. A preliminary analysis of the land molluscs of Malawii. In: Solem A. \& Bruggen A.C. van (eds) World-wide Snails: Biogeographical Studies on non-marine Mollusca: 156-171. Backhuys, Leiden, the Netherlands.

Bruggen A.C. van \& Van Goethem J.L. 1999. Dr. William Adam's iconography of Central and West African Gulella species (Gastropoda Pulmonata: Streptaxidae). Part 3: Nine new species from the D.R. Congo. Bulletin de l'Institut Royal des Sciences Naturelles de Belgique, Biologie 69: 31-45.

Connolly M. 1922. Notes on African Non-marine Mollusca, with Descriptions of Many New Species. Annals and Magazine of Natural History Series 910 (59): 485-517, pl. XIV. http://dx.doi. org/10.1080/00222932208632797

Connolly M. 1930. Descriptions of new molluscs from Central Africa, with notes on other species. Proceedings of the Malacological Society of London 19: 37-48.

Degner E. 1934. Westafrikanische Landschnecken. I. Streptaxiden, Helicarioniden, Vaginuliden. Zoologische Jahrbücher 65: 14-308.

Emberton K.C. 2001. Dentate Gulella of Madagascar (Pulmonata: Streptaxidae). American Malacological Bulletin 16: 71-129.

Emberton K.C. \& Pearce T.A. 2000. Small, High-Spired Pulmonates from Mounts Mahermana, Ilapiry, and Vasiha, Southeastern Madagascar, with Description of a New Genus, and with Conservation Statuses of 15 Streptaxid Species. The Veliger 43 (2): 126-153.

Fischer-Piette E. \& Vukadinovic D. 1974. Les Mollusques Terrestres des Iles Comores. Mémoires du Muséum National d'Histoire Naturelle (Nouvelle Série: Série A, Zoologie) 84, Muséum national d'Histoire naturelle, Paris.

Griffiths O.L. \& Florens V.F.B. 2006. A Field Guide to the Non-Marine Molluscs of the Mascarene Islands (Mauritius, Rodrigues and Réunion) and the Northern Dependencies of Mauritius. Bioculture Press, Mauritius.

Herbert D. \& Kilburn D. 2004. Field guide to the land snails and slugs of eastern South Africa. Natal Museum, Pietermaritzburg.

Herbert D.G. \& Rowson B. 2011. Pupa menkeana Pfeiffer, 1853, type species of the speciose land snail genus Gulella Pfeiffer, 1856: correction of longstanding misidentification and designation of neotype (Mollusca: Eupulmonata: Streptaxidae). African Invertebrates 52 (2): 233-242.

Kobelt W. 1905. Die Raublungenschnecken (Agnatha). Zweite Abtheilung. Streptaxidae und Daudebardiidae. In: Martini \& Chemnitz (eds) Systematisches Conchylien-Cabinet I. 12B (2): 1-211. Bauer und Raspe, Nürnberg.

Kobelt W. 1910. Katalog der lebenden schalentragenden Mollusken der Abteilung Agnatha. Jahrbücher des Nassauischen Vereins für Naturkunde 63: 138-196.

Lange C.N. \& Mwinzi M. 2003. Snail diversity, abundance and distribution in Arabuko Sokoke forest, Kenya. African Journal of Ecology. 41 (1): 61-67. http://dx.doi.org/10.1046/j.1365-2028.2003.00412.x

Morelet A. 1877. Excursion conchyliologique dans i'île d'Anjouan (Johanna). Journal de Conchyliologie 25: $325-347$

Morelet A. 1881. Malacologie des Comores. Récolte de M. Marie à l'île Mayotte. Journal de Conchyliologie 29: 212-240. 
Muratov I.V. 1999. Analysis of the phylogenetic relationships and their systematic implications in the Limacoinei (Zonitinia) infraorder (Gastropoda, Pulmonata, Geophila). Ruthenica 9 (1): 5-26.

Muratov I.V. 2010. Terrestrial molluscs of Cabo Delgado and adjacent inland areas of north-eastern Mozambique. African Invertebrates 51 (2): 255-288. http://dx.doi.org/10.5733/afin.051.0203

Ndalila M. 2011. Land snails of Shimba Hills National Reserve: their distribution, diversity and some aspects of ecology. Lambert Academic Publishing, Saarbrücken.

Pickford M. 2009. Land Snails from the Early Miocene Legetet Formation, Koru, Kenya. Geo-Pal Kenya 2: 1-88.

Preston H.B. 1910. Additions to the non-Marine Molluscan Fauna of British and German East Africa and Lake Albert Edward. Annals and Magazine of Natural History, Series 8 6: 526-536. http://dx.doi. org/10.1080/00222931008692885

Rasband W.S. 1997-2011. ImageJ, U.S. National Institutes of Health, Bethesda, Maryland, USA [online]. Available from http://imagej.nih.gov/ij/. [accessed 30 Mar. 2012]

Richardson C.L. 1988. Streptaxacea: catalog of species. Part I: Streptaxidae. Tryonia 16, Department of Malacology, Academy of Natural Sciences of Philadelphia, Philadelphia.

Rowson B. 2007a. Land molluscs of Zanzibar Island (Unguja), Tanzania, including a new species of Gulella (Pulmonata: Streptaxidae). Journal of Conchology 39 (4): 425-466.

Rowson B. 2007b. Gulella (Juventigulella) ngerezae spec. nov. (Gastropoda, Pulmonata, Streptaxidae), a new endemic land snail from the Ukaguru Mountains, Tanzania. Basteria 71 (4-6): 221-228.

Rowson B. \& Lange C.N. 2007. Two new species of Gulella (Mollusca: Pulmonata: Streptaxidae) from the Taita Hills, Kenya. African Invertebrates 48 (2): 21-32.

Rowson B., Tattersfield P. \& Symondson W.O.C. 2010a. Phylogeny and biogeography of tropical carnivorous land-snails (Pulmonata: Streptaxoidea) with particular reference to East Africa and the Indian Ocean. Zoologica Scripta 40: 85-98. http://dx.doi.org/10.1111/j.1463-6409.2010.00456.x

Rowson B., Warren B.H. \& Ngereza C.F. 2010b. Terrestrial molluscs of Pemba Island, Zanzibar, Tanzania, and its status as an "oceanic" island. ZooKeys 70: 1-39. http://dx.doi.org/10.3897/zookeys.70.762

Schileyko A.A. 2000. Treatise on Recent terrestrial pulmonate molluscs. Part 6: Rhytididae, Chlamydephoridae, Systrophiidae, Haplotrematidae, Streptaxidae, Spiraxidae, Oleacinidae, Testacellidae. Ruthenica Supplement 2, Moscow.

Schileyko A.A. 2003. Treatise on Recent terrestrial pulmonate molluscs. Part 11: Trigonochlamydidae, Papillodermidae, Vitrinidae, Limacidae, Bielziidae, Agriolimacidae, Boettgerillidae, Camaenidae. Ruthenica Supplement 2, Moscow.

Tattersfield P. 1998a. Patterns of diversity and endemism in East African land snails, and the implications for conservation. In: Killeen I.J., Seddon M.B. \& Holmes A.M. (eds) Molluscan Conservation: A strategy for the 21st. Century: 77-86. Journal of Conchology Special Publication 2, The Conchological Society of Great Britain and Ireland.

Tattersfield P. 1998b. Three new species and a new subgenus of Gulella (Gastropoda: Streptaxidae) from Tanzania. Journal of Conchology 36 (2): 31-41.

Tattersfield P., Seddon M.B., Meena C., Kayumbo N. \& Kasigwa P. 1998. Ecology and conservation of the land-snails of the Eastern Arc Mountains. Journal of East African Natural History 87 (1): 119-138. http://dx.doi.org/10.2982/0012-8317(1998)87[119:EACOTL]2.0.CO;2 
Tattersfield P., Seddon M.B., Ngereza C. \& Rowson B. 2006. Elevational variation in diversity and composition of land-snail faunas in a Tanzanian forest. African Journal of Ecology 44: 47-60. http:// dx.doi.org/10.1111/j.1365-2028.2006.00612.x

Tryon G.W. 1885. Testacellidae, Oleacinidae, Streptaxidae, Helicoidea, Vitrinidae, Limacidae, Arionidae. Manual of Conchology: Structrual and Systematic, with Illustrations of the Species. Second Series: Pulmonata 1, Tyron G.W., Philadelphia.

Verdcourt B. 1953. Notes on some East African Gulellae. Basteria 17: 36-42.

Verdcourt B. 1962. Preliminary Keys for the Identification of the Species of the Genus Gulella Pfr. Occurring in East Africa. Annales du Musée Royal de l'Afrique Centrale 106, Musée Royal de l'Afrique Centrale, Tervuren.

Verdcourt B. 1963. The Miocene non-marine mollusca of Rusinga Island, Lake Victoria and other localities in Kenya. Palaeontographica Abt. A 121 (1-3): 1-37.

Verdcourt B. 1983. A list of the non-marine Mollusca of East Africa (Kenya, Uganda, Tanzania, excluding Lake Malawi). Achatina 11: 200-239.

Verdcourt B. 1985. New taxa of Gulella L. Pfr. And Ptychotrema Mörch (Mollusca, Streptaxidae) from Eastern Africa. Journal of Conchology 32 (2): 109-121.

Verdcourt B. 1990. Two Ethiopian streptaxids (Gastropoda: Pulmonata: Streptaxidae). Journal of Conchology 33 (6): 345-354.

Verdcourt B. 1994. A new species of Gulella from SE. Tanzania (Pulmonata: Streptaxidae). Archiv für Molluskenkunde 123 (1/6): 137-139.

Verdcourt B. 1996. A new species of Gulella Pfr. (Gastropoda Pulmonata, Streptaxidae) from NE. Tanzania. Basteria 59 (4-6): 135-137.

Verdcourt B. 2000. Molluscs. In: Burgess N.D. \& Clarke G.P. (eds) Coastal Forests of Eastern Africa: 219-224. IUCN, Gland, Switzerland.

Verdcourt B. 2006. A Revised List of the Non-marine Mollusca of East Africa (Kenya, Tanzania and Uganda, excluding Lake Malawi). Verdcourt B., Maidenhead, UK.

Winter A.J. de 2008. Costigulella primennilus spec. nov., a new minute western African terrestrial snail, with remarks on the genus Costigulella (Gastropoda Pulmonata: Streptaxidae). Zoologische Mededelingen 82 (23): 245-251.

Winter A.J. de, Gomez B.J. \& Prieto C.E. 1999. Sinistrexcisa, a new genus of land snail from Central West Africa with four new species (Gastropoda: Pulmonata: Streptaxidae). Journal of Molluscan Studies 65 (2): 209-221. http://dx.doi.org/10.1093/mollus/65.2.209

Wronski T. \& Hausdorf B. 2010. Diversity and body-size patterns of land snails in rain forests in Uganda. Journal of Molluscan Studies 76 (1): 87-100. http://dx.doi.org/10.1093/mollus/eyp048

Manuscript received: 30 June 2012

Manuscript accepted: 5 December 2012

Published on: 4 February 2013

Topic editor: Rudy Jocqué

Section editor: Kurt Jordaens

Desk editor: Charlotte Thionois 
Printed versions of all papers are also deposited in the libraries of the institutes that are members of the EJT consortium: Muséum National d'Histoire Naturelle, Paris, France; National Botanic Garden of Belgium, Meise, Belgium; Royal Museum for Central Africa, Tervuren, Belgium; Natural History Museum, London, United Kingdom; Royal Belgian Institute of Natural Sciences, Brussels, Belgium; Natural History Museum of Denmark, Copenhagen, Denmark. 